Article

\title{
The Effectiveness of Diamond-like Carbon a-C:H:Si Coatings in Increasing the Cutting Capability of Radius End Mills When Machining Heat-Resistant Nickel Alloys
}

\author{
Sergey N. Grigoriev (D, Marina A. Volosova *, Sergey V. Fedorov (D), Mars S. Migranov, Mikhail Mosyanov, \\ Andrey Gusev and Anna A. Okunkova ${ }^{D}$
}

Citation: Grigoriev, S.N.; Volosova, M.A.; Fedorov, S.V.; Migranov, M.S.;

Mosyanov, M.; Gusev, A.; Okunkova,

A.A. The Effectiveness of

Diamond-like Carbon a-C:H:Si

Coatings in Increasing the Cutting

Capability of Radius End Mills When

Machining Heat-Resistant Nickel

Alloys. Coatings 2022, 12, 206

https://doi.org/10.3390/

coatings12020206

Academic Editor: Vitali Podgursky

Received: 31 December 2021

Accepted: 2 February 2022

Published: 5 February 2022

Publisher's Note: MDPI stays neutral with regard to jurisdictional claims in published maps and institutional affiliations.

Copyright: (C) 2022 by the authors. Licensee MDPI, Basel, Switzerland. This article is an open access article distributed under the terms and conditions of the Creative Commons Attribution (CC BY) license (https:// creativecommons.org/licenses/by/ $4.0 /)$
Department of High-Efficiency Processing Technologies, Moscow State University of Technology STANKIN, 127055 Moscow, Russia; s.grigoriev@stankin.ru (S.N.G.); sv.fedorov@icloud.com (S.V.F.); m.migranov@stankin.ru (M.S.M.); m.mosyanov@stankin.ru (M.M.); gusev.angrey@bk.ru (A.G.); a.okunkova@stankin.ru (A.A.O.)

* Correspondence: m.volosova@stankin.ru; Tel.: +7-916-308-49-00

\begin{abstract}
The main purpose of this paper was to study the efficiency of using diamond-like carbon (DLC) coatings based on a-C:H:Si with a pre-formed CrAlSiN sublayer to increase the cutting ability of ball end mills made of KFM-39 cemented carbide at a speed of 150-250 m/min in milling aircraftgrade Inconel 718, and to assess the DLC coating effect on the quality of the machined surface. DLC coating performance was quantified against uncoated carbide ball end mills and the proven TiN-AlN-TiAlN gradient multilayer coating at elevated temperatures measured by the natural thermocouple method. The temperature near the cutting edge is the factor determining the wear intensity in the tool contact surfaces in milling hard-to-machine nickel alloys to the greatest extent. Thermo-EMF (electromotive force) was recorded and converted into temperatures by calibration charts. The behavior of CrAlSiN-DLC and TiN-AlN-TiAlN coatings was compared with the results of high-temperature tribological tests on a ball-on-disc friction machine. For the CrAlSiN-DLC coating at cutting speeds of 150 and $200 \mathrm{~m} / \mathrm{min}\left(<650^{\circ} \mathrm{C}\right)$, the milling time until critical flank face wear $(0.4 \mathrm{~mm})$ was more than 67 and $50 \mathrm{~min}$, respectively (1.4-1.5 times longer than an uncoated tool and about 1.3 times longer than the TiN-AlN-TiAlN coating). The CrAlSiN-DLC coating was characterized by a minimum adhesion amount.
\end{abstract}

Keywords: DLC; CrAlSiN sublayer; heat-resistant nickel alloy; ball-on-disc; thermo-EMF; end mill; KFM-39 cemented carbide; cutting zone temperature

\section{Introduction}

Precision products made of heat-resistant nickel alloys, such as Inconel 718 and Nicrofer $5219 \mathrm{Nb}$, are more than $50 \%$ of the mass of modern aircraft gas turbine engines due to the unique physical and mechanical properties of these materials and their ability to function under conditions of increased contact stresses, high operating temperatures, and corrosive and erosive effects of vapors and gases [1-5]. The scientific group of Kumar, A., in their study of the formation of fatigue cracks in gas turbine engines [1], studied the liquid corrosion of a nickel alloy with lead, which was a critical factor in the actual destruction of gas turbine engines with a relatively short product life cycle, according to their study and the official conclusion of the investigation. A new approach based on empirical scaling from microstructural dimensions using the simple El Haddad small-crack model and the cracks' length parameter to correlate the small- and large-crack data for nickel-based alloys by adjusting the small-crack driving force was critically evaluated by the research group of McClung, R.C. in [2]. The strengths and limitations of the simple El Haddad model were explored and compared. The research group of Sahoo, B. [3] discussed the bulk properties of a military aircraft's gas turbine engine parts that determine the product life 
and are decided by the aero-thermal degradation and microstructure degeneration of nickel alloy despite aluminide coating. The coarsening of gamma prime and the degeneration of carbides in the bulk material microstructure were evaluated. The research group of Volkov, A.M. [4] investigated the microstructure of gas turbine engine aircraft parts after heat treatment of granulated heat-resistant nickel alloys characterized by high long-term strength at $750{ }^{\circ} \mathrm{C}$ and confirmed the phase stability of the material. The research group of Martinez, S. [5] evaluated the misalignment and geometry distortion of the standard National Institute of Standards and Technology test artifact in the Inconel 718 alloy using laser powder bed fusion. The results of numerical simulations showed that the laser path strategy favors a thermal gradient that partially induces geometrical distortions.

In machining nickel alloys, the working surfaces of cutting tools experience an unfavorable combination of loads, such as the developing high temperatures in the cutting zone combined with high specific pressures on the contact pads contributing to the intense adhesion of the chips coming off with a rake face and the intense abrasion of the flank face in direct contact with the workpiece to be machined [6-10]. The highlighted issues significantly reduce the service life of carbide cutters, increase the probability of cutting edges' brittle fracture, worsen the machined surface quality, and force technologists to reduce the cutting speed and, consequently, the milling productivity.

The following outstanding works can be distinguished from the known scientific groups working in Inconel 718 machining [11-13]. Urbikain Gorka et al. [11], in their recent work, considered the tool geometry, tool position, and laser scanning strategy influence on microstructures, crystallographic textures, and grain morphologies of Inconel 718 samples produced by laser powder bed fusion. The layer thickness of the produced parts influences the evolution of the cutting force in milling.

Wang, B. and Liu, Z.Q. [12] developed a complex approach in a systematization of the last achievements of the influence of cutting parameters and cutting environments, the structure and material of cutting tools on the fundamental factors that govern the machined surface integrity.

Ulutan, D. et al. [13] reviewed surface integrity problems such as residual stresses, white layer and work hardening layers, and microstructural alterations to improve surface qualities of nickel products. They highlighted in their study the following cutting factors that influence surface integrity: cutting speed, feed rate, depth of cut, tool geometry and preparation, tool wear, and workpiece properties.

Wang, J.T. et al. [14] researched the influences of cutting parameters, cutting fluid, and spindle angles on the residual stresses in the ball end milling Inconel 718. They concluded that residual stress distributions are highly influenced by cutting parameters such as the depth of cut and cutting speed. Milling with cooling induces more compressive stresses, and the magnitude of the residual stresses increases in the tensile direction with the increase in spindle angles. In their opinion, the larger the machining parameters, the better for controlling residual stresses in ball end milling that can dramatically influence the service life and performance of the aircraft parts.

Denkena, B. et al., in their work [15], highlight the problem of convex surface quality of a nickel alloy part after additive manufacturing. To solve the global problem of the controlled surface finishing via five-axis ball end milling, they proposed a dynamic simulation model to achieve the required surface quality of aircraft parts.

It should be noted that in the last five years, only four research groups devoted their studies to the ball end milling of nickel aircraft alloys, despite this topic of using last generation complex coatings for the complex tools deserving more attention in the context of high-temperature cutting conditions.

Mills made of cemented carbide with a spherical cutting end to machine spatially complex surfaces of parts made of heat-resistant nickel alloys are more complicated and costly in terms of manufacturing. However, unlike traditional end mills with a rectangular end, they do not have pronounced stress concentrates, which minimizes the probability of brittle fracture of the cutting edges (if rational cutting conditions are assigned) [16,17]. 
In recent years, the range of carbide end mills produced by the tool industry has been so broad that enterprises now have an alternative tool selection to solve any technological problem. A variety of end mills with a spherical cutting part has a conical barrel-shaped geometry that smoothly turns into a spherical end. It is an advanced and promising tool for finishing curved surfaces, which, like the classic ball end mills, should not be deprived of the attention of specialists.

Production experience shows that the milling efficiency of precision products made of heat-resistant nickel alloy primarily depends on the cutting ability of the tool. Therefore, the task of ensuring maximum wear resistance of end mills emerges into prominence [18-22] in combination with an acceptable performance by applying a high cutting speed and reducing the time of auxiliary operations (for tool change). It should be noted that the preservation of a longer time period of cutting ability of ball-shaped end mills aims to solve another technological problem, this being ensuring the possibility of part typical surfaces machining in one setup without the retraction and new plunge-in of the tool. Changing the cutter directly during machining often leads to an error in the shape and size of the part and the appearance of gouges and other unacceptable defects for the aircraft industry [23-25].

Considering that high-temperature nickel alloys have low thermal conductivity and a high tendency to adhere to cemented carbide, the state of the cutting edge (with rake and flank faces forming it) will determine the end mill's cutting ability. The temperature near the cutting edge determines the tool wear intensity in milling Inconel 718 alloys to a greater extent [26-28]. However, despite the existing possibilities of using more heat-resistant oxide and nitride tool ceramics, cemented carbide will remain the primary tool material in the long term due to less brittleness [29-32]. For example, Fernandez-Lucio, P. et al. [33], after testing cemented carbide (uncoated and coated with AlTiN, the thickness of the coating was not provided) and SiAlON ceramics in milling Inconel(R) 718 until the end of their useful life (criterion was tool wear reaching $0.3 \mathrm{~mm}$ or a fatal failure), stated that coated carbide is not ultimately suitable for milling at higher speeds, unlike tool ceramics.

The application of wear-resistant coatings based on nitrides and oxides of refractory metals aims to increase the microhardness of the tool contact pads, ensuring their physicochemical passivity (reducing the coefficient of friction) concerning the material to be machined, a combination of which should increase the end mill's cutting ability [34-37].

It is known from classical works in the field of the theory of cutting materials that the power of heat-generating sources in shaping largely depends on the friction forces on the rake- and flank-working faces of the tool and the work of forces on the contact pads that cause wear $[38,39]$. Therefore, their effectiveness in solving the problem of increasing the tool's cutting ability in cutting nickel alloys [40-43] will, in many respects, depend on the ability of coatings to reduce frictional interaction on the contact pads (while maintaining heat resistance).

Diamond-like carbon (DLC) coatings consist of carbon atoms with both diamond and graphite-like bonds [44-46] and have pronounced advantages over nitride and oxide coatings from the point of view of providing a reduced coefficient of friction on the tool working surfaces. However, the use of DLC coatings for cutting tools under the conditions of cutting difficult-to-machine alloys is limited by their relatively low heat resistance and increased level of internal stresses, which leads to a decrease in the strength of the adhesive bond $[47,48]$. Until recently, the main area of DLC coating application was the high-speed machining of aluminum alloys and other non-ferrous metals when the level of power loads was relatively low and the temperature in the cutting zone did not exceed $450-480{ }^{\circ} \mathrm{C}$. In addition, DLC coatings are in their most comfortable conditions in such a temperature range, and many authors have experimentally confirmed their effectiveness in cutting "light" processed materials [49]. The authors of this work provided a threefold increase in tool wear resistance and a significant improvement in the quality of the machined part by single-layer hydrogenated DLC coating (a-C:H type) deposition to end mills when machining the aluminum alloy $\mathrm{AlCuMg}_{2}$. 
In recent years, great progress has been made by various research teams in the area of improving DLC coatings [50-53]. Various technological approaches are associated with alloying coatings by various metals and metalloids, in particular silicon, to stabilize the tribological properties of DLC coatings under high-temperature heating conditions. Transition and intermediate sublayers are preliminarily formed, which have proven to be highly effective under certain conditions to reduce the level of stresses in the DLC coating deposed on the cemented carbide and to ensure increased strength of the coating adhesive bond to the substrate [54-56]. Modern DLC coatings remain underestimated although they have specific prospects in increasing the tool cutting ability in milling heat-resistant nickel alloys.

The aim of this work was to study the ability of DLC coatings based on a-C:H:Si with a CrAlSiN nitride sublayer to withstand thermal loads in a wide temperature range (varied by choosing a different speed milling mode such as 150, 200, and $250 \mathrm{~m} / \mathrm{min}$ ). The efficiency of DLC coating deposed to cemented carbide ball end mills was evaluated compared to uncoated ball end mills and the samples coated with the well-proven multi-layer gradient TiN-AlN-TiAlN coating under high-temperature conditions (at 20, 550, 650, 850 ${ }^{\circ} \mathrm{C}$ ). During the experiments, the particular focus was on assessing the temperature in the cutting zone as the most important and, in many ways, informative parameter. The thermo-EMF (electromotive force) was recorded, which was converted into temperature values according to the corresponding calibration charts using the method of natural thermocouple in the cutting zone. For the first time, the authors compared the behavior of CrAlSiN-DLC and TiN-AlN-TiAlN coatings deposed to ball end mills under operating conditions at different cutting temperatures, with the results of high-temperature tribological tests received on a friction machine. The new experimental results on the assessment of the cutting ability of cemented carbide ball end mills with CrAlSiN-DLC coatings at different levels of thermal loads as well as establishing the effect of coatings on the state of the machined surface of a nickel alloy part can be a step towards expanding the areas of technological application of DLC coatings and their implementation based on new technical solutions for the needs of the aviation industry.

\section{Materials and Methods}

\subsection{Cutting Tools and Materials to Be Machined}

Spherical end mills were used for the experiments, designed for machining free-form surfaces (FFS) in parts made of difficult-to-machine materials. Figure 1 shows a general view of the design of the end mill. Spherical end mills with the following design and geometrical parameters were used: number of teeth was 4; diameter of cut was $12 \mathrm{~mm}$; ball nose radius was $6 \mathrm{~mm}$; length of cut was $30 \mathrm{~mm}$; overall length was $75 \mathrm{~mm}$.

KFM 39 tungsten-cobalt carbide manufactured by Konrad Micro Drill (Kulmbach, Germany) was used as a tool material. Table 1 shows the characteristics of the tool carbide.

Table 1. Characteristics of KFM 39 cemented carbide.

\begin{tabular}{ccc}
\hline Characteristic & Measuring Unit & Value \\
\hline $\begin{array}{c}\text { Tungsten carbide content (including } \\
\text { alloying substances) }\end{array}$ & $(\mathrm{wt} . \%)$ & 91.0 \\
Cobalt content & $(\mathrm{wt} . \%)$ & 9.0 \\
Density & $\left(\mathrm{g} / \mathrm{cm}^{3}\right)$ & $14.40 \pm 0.15$ \\
Coercive force & $\left(\mathrm{kA} / \mathrm{m}^{3}\right)$ & $36.0 \pm 2.8$ \\
HV30 hardness & $(\mathrm{ISO} 3878)$ & $1950 \pm 50$ \\
HRC hardness & $(\mathrm{ISO} 3738)$ & 93.9 \\
Crack resistance, $\mathrm{K}_{\mathrm{IC}}$ & $\left(\mathrm{MPa} \cdot \mathrm{m}^{1 / 2}\right)$ & 9.3 \\
Flexural strength & $\left(\mathrm{N} / \mathrm{mm}^{2}\right)$ & 4500 \\
Average particle size of & $(\mu \mathrm{m})$ & 0.4 \\
tungsten carbide & &
\end{tabular}




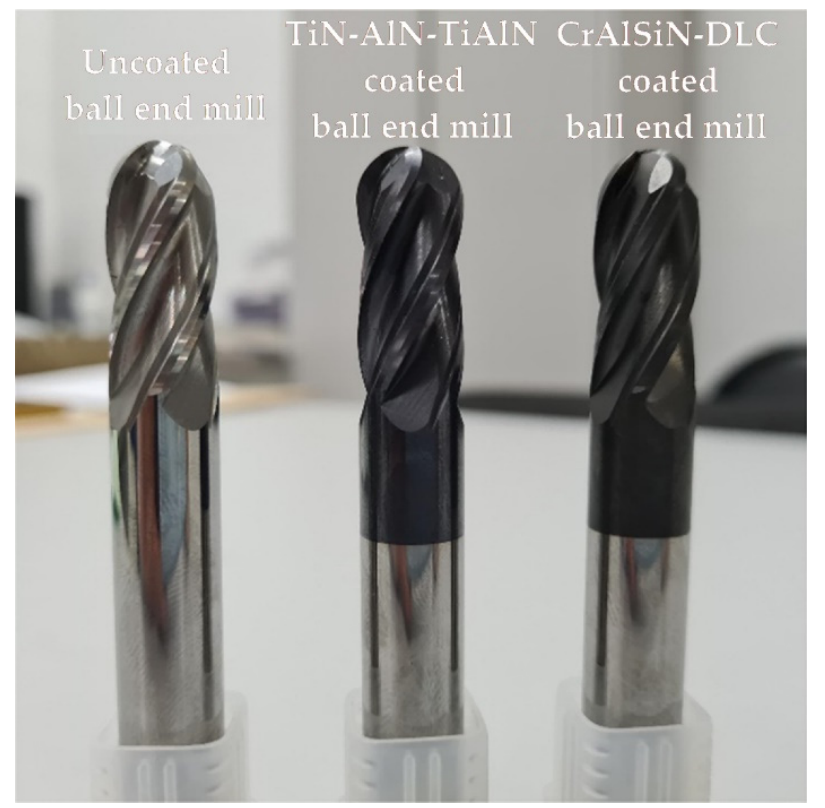

Figure 1. Design of end mills used in research.

The material to be machined was a nickel-based, heat-resistant alloy XH45MBTJuBP, according [57] (the closest analog of Inconel 718). Table 2 shows the composition of the machined alloy. The basis of the specified alloy is an austenitic solid solution of the nickelchromium-iron system. In practice, the alloy is used for the highly loaded elements of load-bearing structures and other parts of gas turbine engines operating in various climatic conditions at temperatures up to $800{ }^{\circ} \mathrm{C}$. The workpiece used in the research was a hotrolled bar that was $55 \mathrm{~mm}$ in diameter. The alloy had a hardness of 320 (on the HB scale) and strength of $1080 \mathrm{MPa}$.

Table 2. Chemical composition of XH45MBTJuBP alloy used in research.

\begin{tabular}{cccccccccccccc}
\hline Element & Ni & Fe & Cr & Mo & Nb & W & Ti & Al & Mn & Si & C & P & S \\
\hline Content (wt. \%) & 44.1 & 30.0 & 14.3 & 4.0 & 1.1 & 2.5 & 2.0 & 1.0 & $\leq 0.6$ & $\leq 0.3$ & $\leq 0.1$ & $\leq 0.015$ & $\leq 0.01$ \\
\hline
\end{tabular}

\subsection{Technology and Equipment for the Coatings' Deposition on End Mills}

The technology of coating spherical end mills included three main stages:

- Preliminary ultrasonic cleaning of the tool, rinsing in a particular alcohol-containing solution, and drying;

- Etching in a gas discharge by the source of a beam of fast neutral molecules to improve the strength of the adhesive bond of the formed coatings, cleaning and thermal activation of the outer surfaces of the tool in the working vacuum chamber of the setup [58-64];

- Deposition of nitride and DLC layers [51,58].

The authors [58] have discussed the ( $\mathrm{Cr}, \mathrm{Al}, \mathrm{Si}) \mathrm{N}-(\mathrm{DLC}-\mathrm{Si})$ system composite coatings on the $\left(\mathrm{Al}_{2} \mathrm{O}_{3}+\mathrm{TiC}\right)$ ceramic cutting tool and the performance properties. The studies substantiated the need for the deposition a $(\mathrm{Cr}, \mathrm{Al}, \mathrm{Si}) \mathrm{N}$ transition sublayer between a ceramic tool and the DLC-Si coating and the influence of the Si content on the life of a ceramic cutting tool. The research group of Jeon, Y. [59] investigated the tribological properties of ultrathin films with a single metal layer of chromium, nickel, and titanium between the Si substrate and the thin film. Three different metals (chromium, nickel, and titanium) were used as the interlayers between the Si substrate and DLC thin film, then, the $\mathrm{Cr}$ interlayer was found to be the most suitable to improve the tribological behavior of the DLC coating. Both of these works used etching in a gas discharge. 
A. Metel [60] developed a vapor source, the flat target of a hollow cathode, isolated from the cathode and sputtered by $1-4-\mathrm{keV}$ argon ions. The higher energy of the atoms improved the quality of $\mathrm{Ti}(3) \mathrm{SiB}(2)$ coatings, their deposition rate of $10-20 \mathrm{mu} \cdot \mathrm{m} / \mathrm{h}$ at 1 A current in the target circuit, and 3-keV energy of sputtering ions that was one order of magnitude higher in comparison with the target sputtering in a planar magnetron. In [61], it was shown that the formed plasma of a broad beam of fast neutral molecules for cutters nitriding proved that fast molecules play a leading role in gas ionization. An anode immersed in the plasma reduces plasma nonuniformity to $10 \%$ when the discharge voltage amounts to 200-300 V and raises plasma density by an order of magnitude. A new beam-assisted deposition technique featuring fast neutral molecule beams instead of conventional ion beams [62] ensured better treatment stability and reliability, eliminated the damage of conductive films with unipolar arcs, and substantially reduced the number of beam-induced defects in semiconductive and dielectric coatings. An experimental study of a fast argon atom beam source [63] was carried out to research the influence of the zone diameter of a homogeneous substrate etching by a broad beam of fast argon atoms accelerated between a plasma emitter inside the hollow cathode and secondary plasma in the working vacuum chamber. The diameter of the homogeneous etching zone was mainly influenced by the angular characteristics of accelerated particles in the grid plane. The diameter was raised with a decrease in energy and an increase in the beam current. A source of slow metal atoms produced beam-assisted deposition of cutting tool coatings [64]. Fast gas molecules allowed keeping the ratio of metal atom flow density to that of fast molecules constant and maintaining uniformity of the coating properties. Fast molecules are produced due to charge-exchange collisions of ions accelerated by bias difference between a plasma emitter inside the source and secondary plasma inside the chamber.

The method of vacuum arc deposition was used for the deposition of a two-component nitride coating TiN-AIN-TiAlN and a three-component sublayer CrAlSiN, in which the metal component of the plasma is formed upon evaporation of the cathode material from the cathode spots of the arc discharge, and the reactive gas is supplied to the working zone in an ionized state. A plasma-chemical, gas-phase deposition of carbon condensate was used for the DLC coating's deposition through a chemical reaction and the decomposition of the gas mixture components (the original technology, patented by Platit, Selzach, Switzerland, was taken as a basis).

A functional diagram of a hybrid vacuum-plasma setup, which makes it possible to form coatings by vacuum-arc and gas-phase deposition, is shown in Figure 2. The working vacuum chamber is made in the form of a hexagonal prism, on the flanges of which a pair of electric arc evaporators with cathodes are located, equipped with arc magnetic field systems and control of the trajectory of motion of the cathode spots. The cathodes have the shape of a truncated cone and are obtained by sintering powder materials in a vacuum. Two oppositely installed cathodes ( $\mathrm{Ti}$ and $\mathrm{Al}$ ) participated in the work during the deposition of the TiN-AlN-TiAlN coating, $\mathrm{Cr}$ and AlSi, respectively, and the working gases were supplied to the chamber via a multi-channel gas injection system (each channel was equipped with an individual flow regulator) during the CrAlSiN sublayer deposition.

The original design of the setup allows for planetary rotation of the machined end mills due to the work table rotation and tool sample holders. It is possible to form both monolayer coatings and multilayer coatings with alternating layers, particularly TiN-AlN, by setting the required rotation frequencies of the table and holders and their synchronization by using the installation control system. When the samples enter the plasma flow generated in a vacuum by an electric arc evaporator, a layer is deposed from the material from which the evaporator cathode is made. The next layer is deposited after turning the working table into another evaporator's zone, and the samples ingress into the plasma flow region. The process is repeated depending on the designed structure and the required coating thickness. 


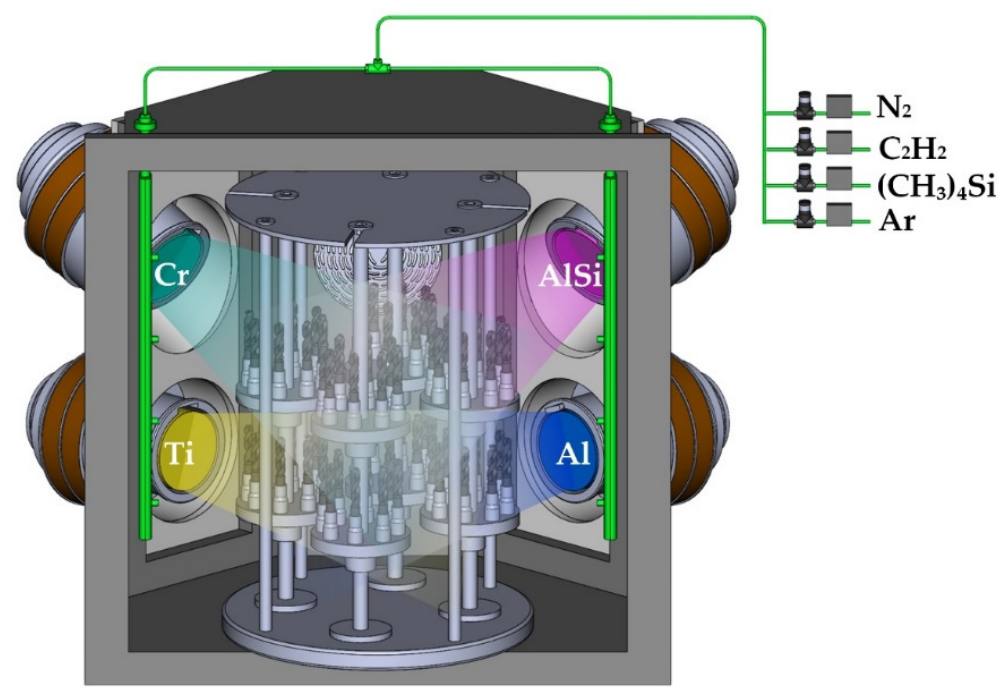

Figure 2. Schematic diagram of a hybrid vacuum-plasma installation for vacuum arc and gas-phase coatings' deposition.

An $\mathrm{Ar}$ and $\mathrm{N}_{2}$ gas mixture in a $95 \% \mathrm{~N}_{2}$ and $5 \%$ Ar ratio was admitted into the chamber. The pressure was set at $0.9 \mathrm{~Pa}$ for the nitride coating's deposition. The temperature in the chamber was maintained with the help of heaters at a level of $550{ }^{\circ} \mathrm{C}$. The following currents were supplied to the cathodes to ensure the most dense and uniform plasma flow: during TiN-AlN-TiAlN deposition, for Ti cathode-100 A, for Al-120 A; during the deposition of CrAlSiN, for the Cr cathode-100 A, for AlSi-120 A. Negative bias of $50 \mathrm{~V}$ was supplied from the reference voltage source to the planetary rotation device, and the process of condensation of coatings was carried out. The total deposition time of the TiN-AlN-TiAlN coating was $120 \mathrm{~min}$, and the CrAlSiN sub-coat was $65 \mathrm{~min}$. The formation of the DLC-based outer coating consisted of three stages. At the beginning of the process, $10 \mathrm{~min}$ before the completion of the formation of the preceding nitride sublayer of CrAlSiN, tetramethylsilane was supplied into the vacuum chamber, bringing the gas mixture to a ratio of $80 \% \mathrm{~N}_{2}, 15 \%\left(\mathrm{CH}_{3}\right)_{4} \mathrm{Si}$, and $5 \%$ Ar (to form a transition layer and voltage reduction in the DLC coating). Then, the vacuum-arc evaporators were turned off, and the temperature in the chamber dropped to $200{ }^{\circ} \mathrm{C}$ (the temperature was further maintained by the heaters). A negative bias of $500 \mathrm{~V}$ was applied to the planetary rotation device, and a glow discharge was ignited. A gradient DLC layer was formed when a gas mixture was supplied into the chamber in a ratio of $75 \% \mathrm{~N}_{2}, 20 \% \mathrm{Ar}$, and $5 \%\left(\mathrm{CH}_{3}\right)_{4} \mathrm{Si}$ and at a pressure of $1.5 \mathrm{~Pa}$ during the first $20 \mathrm{~min}$. In the final stage, within $1 \mathrm{~h} 40 \mathrm{~min}$ of a gas mixture ratio of $45 \% \mathrm{C}_{2} \mathrm{H}_{2}, 53 \% \mathrm{Ar}$, and $2 \%\left(\mathrm{CH}_{3}\right)_{4} \mathrm{Si}$ and a chamber pressure of $0.8 \mathrm{~Pa}$, as a result of the decomposition of acetylene, carbon atoms were deposited on the end mills surface in the form of a DLC coating. It should be noted that the Si content in the carbon film, which affects the DLC coating characteristics, depends on the $\left(\mathrm{CH}_{3}\right)_{4} \mathrm{Si}$ content in the gas mixture, which is controlled by the gas flow rate in the channel. Earlier research by the authors found that the rational Si content in the DLC coating is $3-4 \%$. In this work, the ratio of gases in the mixture at the final stage of DLC coating formation was established based on this.

\subsection{Evaluation of the Coated Specimens' Characteristics Outside the Cutting Process}

Scanning electron microscopy (SEM) was conducted using a TESCAN VEGA microscope (Tescan, Brno, Czech Republic) with a thermionic tungsten cathode and TESCAN MIRA3 (Tescan, Brno, Czech Republic) to assess the morphology of the formed coatings. The structure and thickness of the formed coatings on the specified equipment were examined by SEM analysis of thin sections of the working part of the end mills by a specialized technological line of Struers (Struers ApS, Ballerup, Denmark). 
Transmission electron microscopy (TEM) was used to study structure and thickness. For this purpose, thin lamellas were cut out of the coated sample using a Quanta 200 3D focused ion beam setup (FEI Company, Hillsboro, OR, USA); they were further examined on a transmission microscope JEM-2100F (JEOL, Tokyo, Japan).

The principle of nano-identification by a three-edged Berkovich pyramid was used in the Nano Hardness Tester by CSEM instruments (Alpnach, Switzerland) [51] to assess the microhardness of the coated hard-alloy samples. Such measurements are considered the most informative because they minimize the influence of the tool substrate hardness on the values of the estimated characteristics of the coatings. In the experiments, the penetration depth of the indenter was $380 \mathrm{~nm}$ and the applied load was $4.0 \mathrm{mN}$.

A preliminary analysis of the abrasion resistance of the end mills with two coatings was carried out through rapid tests on a Calotest instrument from CSM Instruments (Alpnach, Germany). A rotating sphere was placed on the test samples of cutters with a load of $0.5 \mathrm{~N}$ and an abrasive suspension was fed into the contact zone. Suspension particles in the contact zone and applied external forces led to local abrasion of the cutters' surface layer areas. As the tests were carried out directly on the tool specimens (in the form of a cylinder) rather than on flat samples, the wear hole had the shape of an ellipse and not a circle, as is the case in standard tests. Therefore, optical analysis of the size of the holes made it possible to determine the volume of the abraded surface at different periods.

The surface layer friction coefficient of hard-alloy samples made of KFM 39 with coatings was evaluated on a TNT friction machine from Anton Paar TriTec (Graz, Austria). For tribological tests, experimental specimens were made in the form of disks with a diameter of $18 \mathrm{~mm}$ and a height of $6 \mathrm{~mm}$. The $6 \mathrm{~mm}$ ball-like counter bodies were made of a nickel alloy to be machined. The ball-on-disc scheme was used, corresponding to the ASTM G99 17 standard. During the tests, the following modes were established: an applied load of $1 \mathrm{~N}$; a radius of movement of $2 \mathrm{~mm}$; a sliding speed of $100 \mathrm{~mm} / \mathrm{s}$. The tests were carried out over a wide range of temperature exposures.

\subsection{Evaluating the Cutting Performance of Coated End Mills during Milling}

Evaluation of the cutting ability of ball end mills was carried out on a CTX beta 1250 TC turning and milling machine from DMG MORI (Bielefeld, Germany) equipped with a Siemens CNC system (Munich, Germany). The machining strategy scheme that was used in the tests was as follows (Figure 3a). The end mill that was fixed in a collet chuck performed a main rotational movement at cutting speed $v_{\mathrm{c}}$ and moved along the workpiece axis (feed rate, $v_{\mathrm{f}}$ ) at a depth of cut $a_{\mathrm{p}}$. The workpiece to be machined in the form of a bar was provided an auxiliary rotational movement at speed $v_{\mathrm{w}}$. The cutting process was carried out at the following modes: $v_{\mathrm{c}}$ of 150,200 , and $250 \mathrm{~m} / \mathrm{min} ; f_{\mathrm{z}}$ of $0.05 \mathrm{~mm} /$ tooth; $a_{\mathrm{p}}$ of $0.3 \mathrm{~mm} ; v_{\mathrm{w}}$ of $1.7 \mathrm{~m} / \mathrm{min}$.

The cutting conditions were chosen based on the need to provide a wide range of thermal loads on the cutting part of end mills with DLC coatings and also taking into account the recommendations of the leading manufacturers of cemented carbide ball end mills for cutting hard-to-cut alloys, such Guhring (Albstadt, Germany) and Karnasch Professional Tools (Heddesheim, Germany) and others.

During the experiments, the research team discussed adding up the speeds for a summary value taking into account $v_{\mathrm{w}}$. However, such a difference does not show a significant impact on the temperature in the cutting zone.

The test specimens of the tool were divided into 9 groups (each group had 5 specimens): end mills without coating, end mills with TiN-AlN-TiAlN coating, end mills with CrAlSiNDLC coating. These were tested at cutting speeds of 150, 200, and $250 \mathrm{~m} / \mathrm{min}$. There were at least 10 repetitions for each type of coating and ball end mill in the determined cutting conditions. 


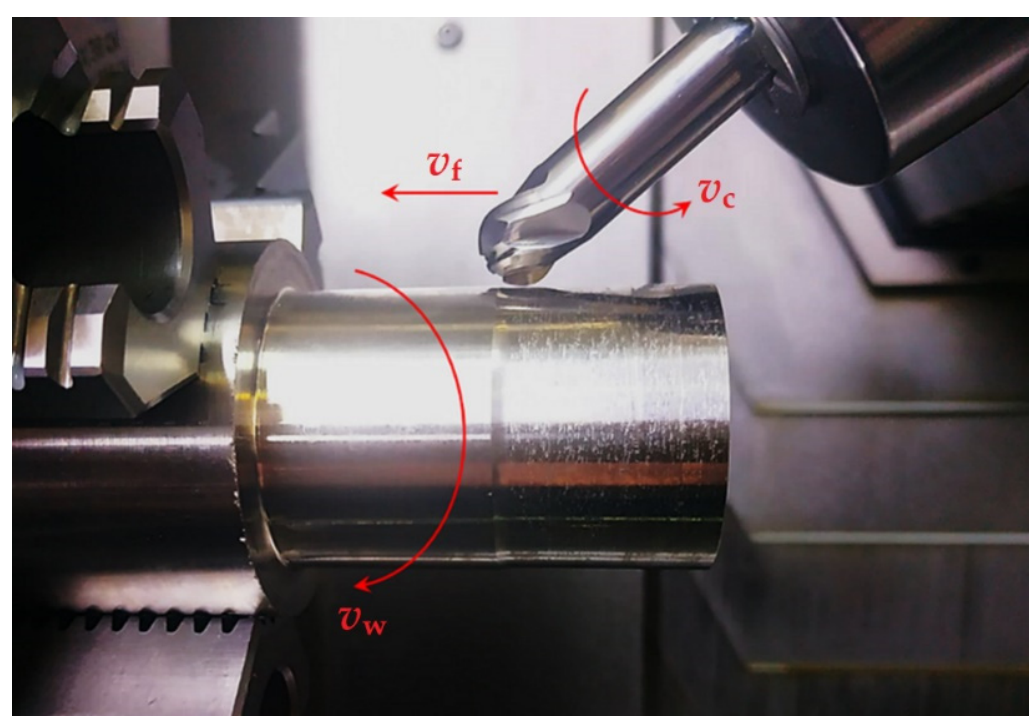

(a)

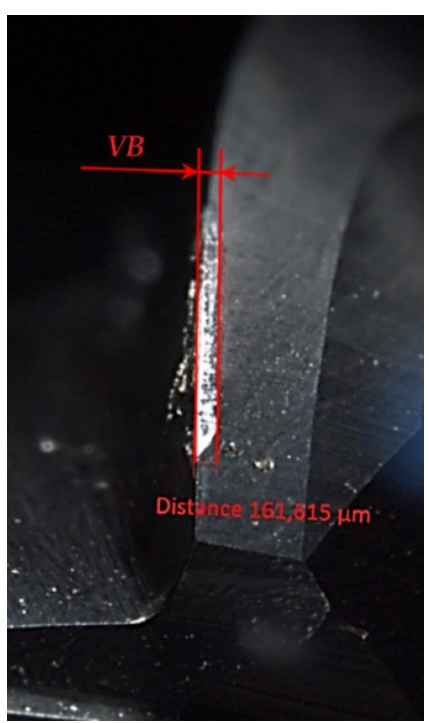

(b)

Figure 3. A strategy for performing a milling/turning test on ball end mills to evaluate cutting properties (a) and tool wear on the flank face criterion, $V B(\mathbf{b})$.

The milling time until the tool wear on the flank face reached the critical value of $0.3 \mathrm{~mm}$ was taken as a criterion for the cutting ability of ball end mills' evaluation. A Stereo Discovery V12 metallographic optical microscope from Carl Zeiss (Oberkochen, Germany) was used for wear evaluation. Each of the four teeth of the ball end mill was measured, and the average of the reported wear was taken into account in collecting static data. Figure $3 \mathrm{~b}$ shows a diagram of the measurement of the tool wear on the flank face of a ball end mill using the built-in micro-meter ruler of the microscope. At the end of the tests, graphs of changes in wear values versus milling time were drawn, based on which, the average time until the critical wear reaching moment was calculated.

The state of the workpiece surface layer is an object of close attention for technologists at enterprises because the cutting of nickel alloys is accompanied by an increased adhesive interaction of the tool and workpiece materials, and a large number of adhesions are present not only on the working surfaces of the tool but also directly on the workpiece (chip particles are firmly welded to the processed part) $[7,17,65]$. However, a large amount of stock material at the cutting edge often requires additional operations before abrasive machining can be finished. In addition, their mechanical removal can damage the surface layer of the critical parts. Therefore, the state of the machined part surface was examined on a Hommel Tester T8000 profilograph-profilometer from JENOPTIK Industrial Metrology (VillingenSchwenningen, Germany) when assessing the cutting ability of the tool in addition to dimensional wear.

\subsection{Temperature Assessing in the Cutting Zone Using the Natural Thermocouple Method}

The natural thermocouple method is one of the simplest and most accurate methods for experimentally estimating the temperature under the cutting conditions compared to the methods of artificial and semi-artificial thermocouples. When the workpiece and the cutter are combined into a closed electrical circuit, the magnitude of the thermoelectromotive force occurring in the thermoelement is proportional to the temperature of the sliding "junction" of the formed thermocouple. A thermocouple "junction" can be presented as a large number of parallel-connected thermocouples with internal resistance. It is important to note that the temperature in the contact stabilizes within $5 \mathrm{~s}$ from the start of cutting and it allows us to estimate the average temperature of the cutting zone without focusing on one of the contact surfaces with an error of no more than $6^{\circ} \mathrm{C}$.

The study of the temperature on the contact pads during cutting was carried out by the method of a natural thermocouple (the average temperature during milling was 
estimated) [66-69]. Figure 4a shows a functional diagram of a system for measuring the cutting temperature, implemented based on a turning-milling machine. Visualization of the temperature distribution at the cutting edge and adjacent layers of tool material is shown in Figure $4 \mathrm{~b}$. During the experiments, the part and the end mill were isolated from each other in order to eliminate errors from the so-called "parasitic" thermo-EMF. Thermo-EMF was measured in the range of 5.0-5.5 min after the start of cutting at the stage of the steady-state process (after the running-in stage). Mercury current collectors and a recording device of the Endim 622 model (VEB Feinmesszeugfabrik, Suhl, Germany) were used to register and record the thermo-EMF value. Experimental data were received and processed in an information processing and control rack.

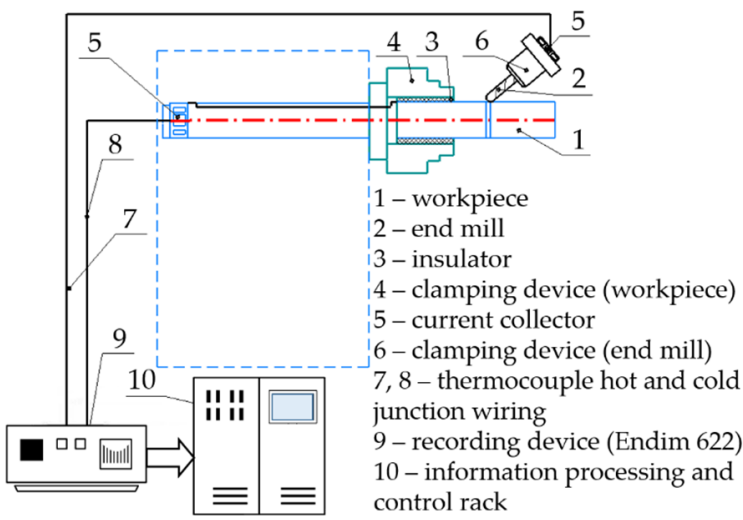

(a)

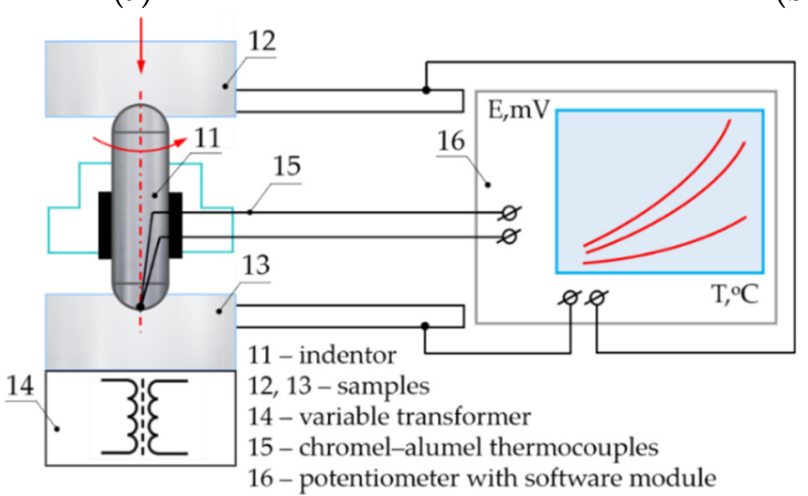

(c)

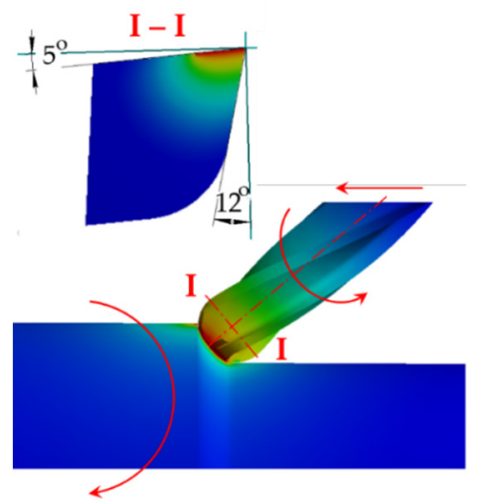

(b)

igure 4. Functional diagram of a system based on a turning-milling machine for measuring the average cutting temperature (a); visualization of the temperature distribution at the cutting edge and adjacent layers of tool material (b); and calibration diagram of a natural thermocouple (c).

The application package TemPole (Ufa Aviation State Technical University, Ufa, Russia) was used to process the array of data on the measurement of thermo-EMF. An original system was used for calibrating natural thermocouples based on a differential heating scheme and a model of local contact of single microroughness of the tool and processed materials to convert the obtained values of thermo-EMF during cutting into temperatures. A distinctive feature of this approach is that the natural thermocouple was calibrated at different pressures at the contact during loading and unloading, and heating was carried out by an electro-contact method. Figure 4c shows the calibration scheme for a natural thermocouple. The calibration process was based on a differential scheme. A model of local contact of a single microroughness of a tool was used as a hot junction of a thermocouple. It was made in the form of a two-sided spherical indenter made of tool material under a normal load, embedded in plane-parallel samples of a nickel alloy. In this case, the indenter was provided a rotational motion, and the lower sample was heated by the electrocontact method using a regulating transformer. The actual contact temperature was 
recorded with a control chromel-alumel thermocouple with a diameter of $0.03-0.05 \mathrm{~mm}$ and the Endim recording device, on which the thermo-EMF of a natural thermocouple was recorded. The heating temperature was changed due to a change in the strength of the transmitted electric current, the regulating transformer. The contact zone was heated by an electrical installation, which was a step-down and control transformer. The readings of the thermo-EMF of the control thermocouple during cooling and various modes of loading and unloading of the contact zone were recorded, and then they were converted to the corresponding temperature values according to the calibration tables. Comparison of temperature values while machining nickel alloy in a wide range of cutting speeds and visualization of the temperature distribution on the cutting edge and adjacent layers of tool material were carried out using a specialized module based on the Deform 3D software package from SFTC (Columbus, OH, USA).

\section{Results}

\subsection{Structure and Properties of Coatings Deposed to End Mills}

Figure 5 shows the surface morphology of the cutting edge of the tool with various coatings. It can be seen that the nitride and DLC coatings were uniformly formed on the working surfaces of the end mills and did not radically change the cutting edge radius. SEM images of the surface layer structure of TiN-AlN-TiAlN-coated carbide specimens (Figure $5 \mathrm{~b}$ ) demonstrate that the thickness and quantity of TiN and AlN nanolayers can be controlled by using separate $\mathrm{Ti}$ and $\mathrm{Al}$ cathodes and by adjusting the table and specimen holder rotation frequencies. The outer layer of the TiAlN coating had a classic columnar structure, and its microhardness was $31 \pm 2 \mathrm{GPa}$, following the measurements performed. The total thickness of the TiN-AlN-TiAlN coating was $4.6-4.8 \mu \mathrm{m}$. It is noticeable that individual microdroplets were encountered on the surface during the deposition of the TiN-AlN-TiAlN coating, despite the presence of a filtration system in the vacuum-plasma installation. These microdroplets are a distinctive feature of the deposition of coatings from a stream of multicomponent plasma of a vacuum-arc discharge (especially during the evaporation of aluminum). Previous experience shows that forming a small amount of microdroplets is not critical for a sufficiently large tool (which includes milling cutters with a diameter of $12 \mathrm{~mm}$ ) because they do not have a pronounced effect on the strength of the adhesive bond between the coating and the carbide substrate. The TEM image of the structure of the surface layer of cemented carbide samples coated with CrAlSiN-DLC (Figure $5 \mathrm{c}$ ) demonstrates that the nitride sublayer had a classic columnar structure, and the outer DLC layer based on a-C:H:Si had an amorphous structure, in which no pronounced grains and boundaries between them were observed. The microhardness of the DLC layer was $27 \pm 1 \mathrm{GPa}$, and the total coating thickness was 4.0-4.2 $\mu \mathrm{m}$.

The results of the tests for resistance to abrasive wear of the ball end mills with various coatings demonstrate (Figure 6) that the presence of the two investigated types of coatings within 10 min of testing had a significant effect on the volume of the worn surface layer. At the same time, the CrAlSiN-DLC coating, despite a slightly lower microhardness within $10 \mathrm{~min}$, more effectively protected the carbide from abrasion compared to the TiN-AlNTiAlN coating. However, no differences in the volume of the worn surface layer were observed for samples with TiN-AlN-TiAlN and CrAlSiN-DLC coatings by the 15th minute of testing.

The dependences of constructed histograms of the friction coefficients of the surfaces of hard-alloy specimens with various coatings on the length of the friction path with varying temperature test conditions are of interest (Figure 7). At room temperature, an uncoated cemented carbide had a friction coefficient of about 0.8 , specimens with a TiNAlN-TiAlN coating had one of 0.5 , and those with a CrAlSiN-DLC coating had one of 0.1 . High-temperature heating of the specimens radically changes the conditions of frictional interaction. The friction coefficient of the uncoated cemented carbide specimens was in the range of $0.8-1.1$ at a test temperature of $550^{\circ} \mathrm{C}$. Coatings formed on hard-alloy specimens significantly reduce this indicator; for the TiN-AlN-TiAlN coating, the friction coefficient 
was 0.6-0.8, and for specimens with the CrAlSiN-DLC coating, it was 0.3-0.6. At the same time, the friction coefficient increases with an increase in the friction path for the two investigated types of coatings. At a test temperature of $650{ }^{\circ} \mathrm{C}$, the change in the friction coefficient was similar, but its values continued to increase. Therefore, the friction coefficient was 1.1-1.3 for specimens of the cemented carbide without coating, for the TiNAlN-TiAlN coating this was 0.7-1.1, and for the CrAlSiN-DLC coating this was 0.4-0.9. At a test temperature of $800{ }^{\circ} \mathrm{C}$, the nature of the change in the friction coefficient changed radically. For uncoated cemented carbide specimens along the entire friction path, the friction coefficient changed abruptly from 1.1 to 1.6. The friction coefficient for specimens with the TiN-AlN-TiAlN coating decreased (in comparison with tests when heating to $650{ }^{\circ} \mathrm{C}$ ) and amounted to 0.7-1.0. Specimens with CrAlSiN-DLC coatings in all other temperature conditions showed lower friction coefficient values when they demonstrated a friction coefficient of $0.8-1.3$ at $800{ }^{\circ} \mathrm{C}$, which is noticeably higher than the value of the mentioned indicator for the TiN-AlN-TiAlN coating.

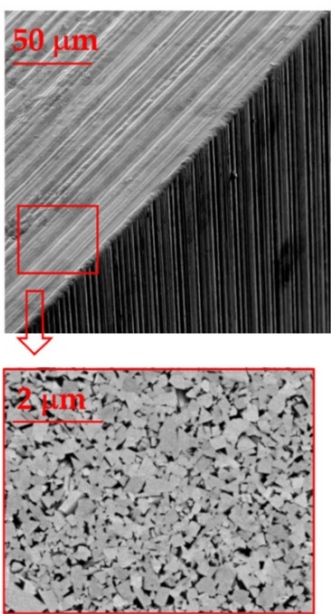

(a)
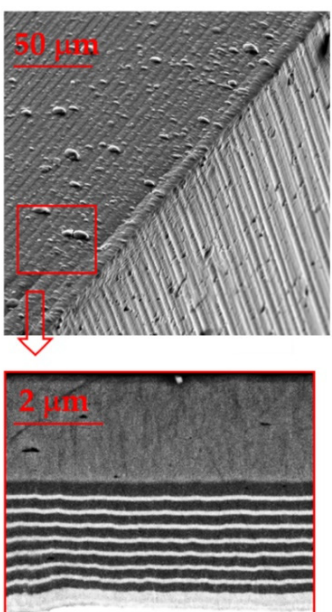

(b)
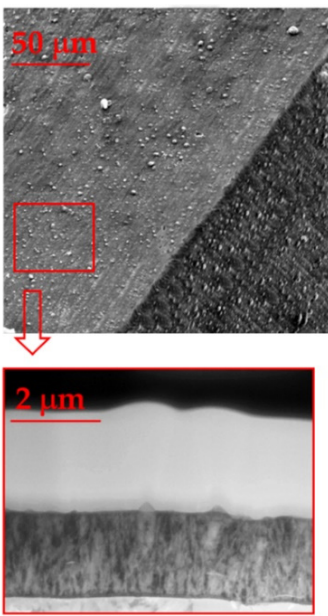

(c)

Figure 5. Surface morphology and surface layer structure of ball end mills: (a) uncoated cemented carbide; (b) with TiN-AlN-TiAlN coating; (c) with CrAlSiN-DLC coating.
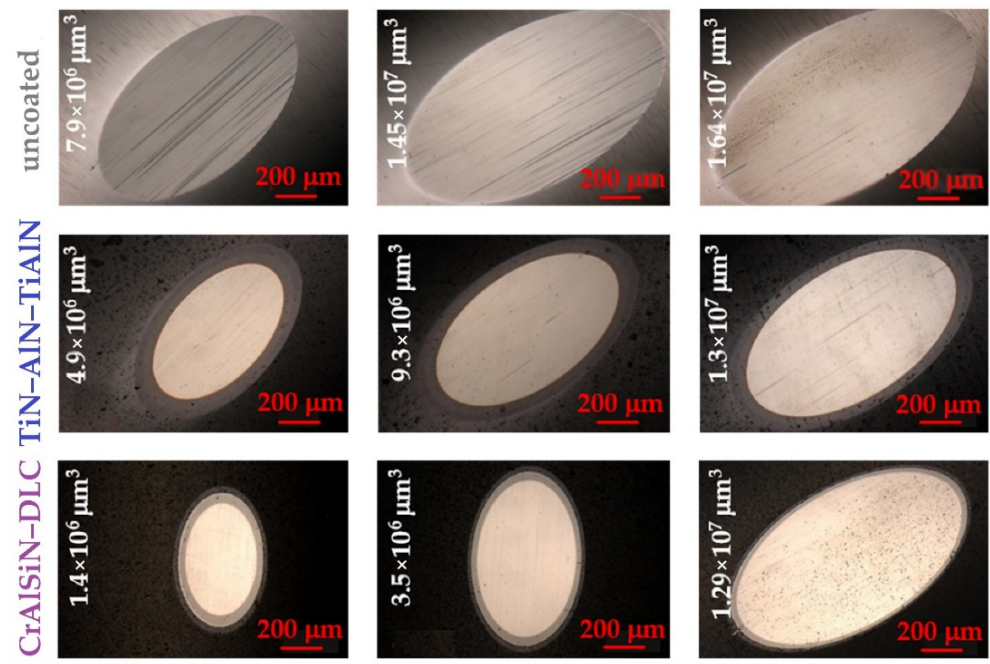

(a)

(b)

(c)

Figure 6. The type of wear holes and the volume of the worn surface versus the time of the abrasion test for ball end mills with different coatings: (a) at $5 \mathrm{~min}$; (b) at $10 \mathrm{~min}$; (c) at $15 \mathrm{~min}$. 

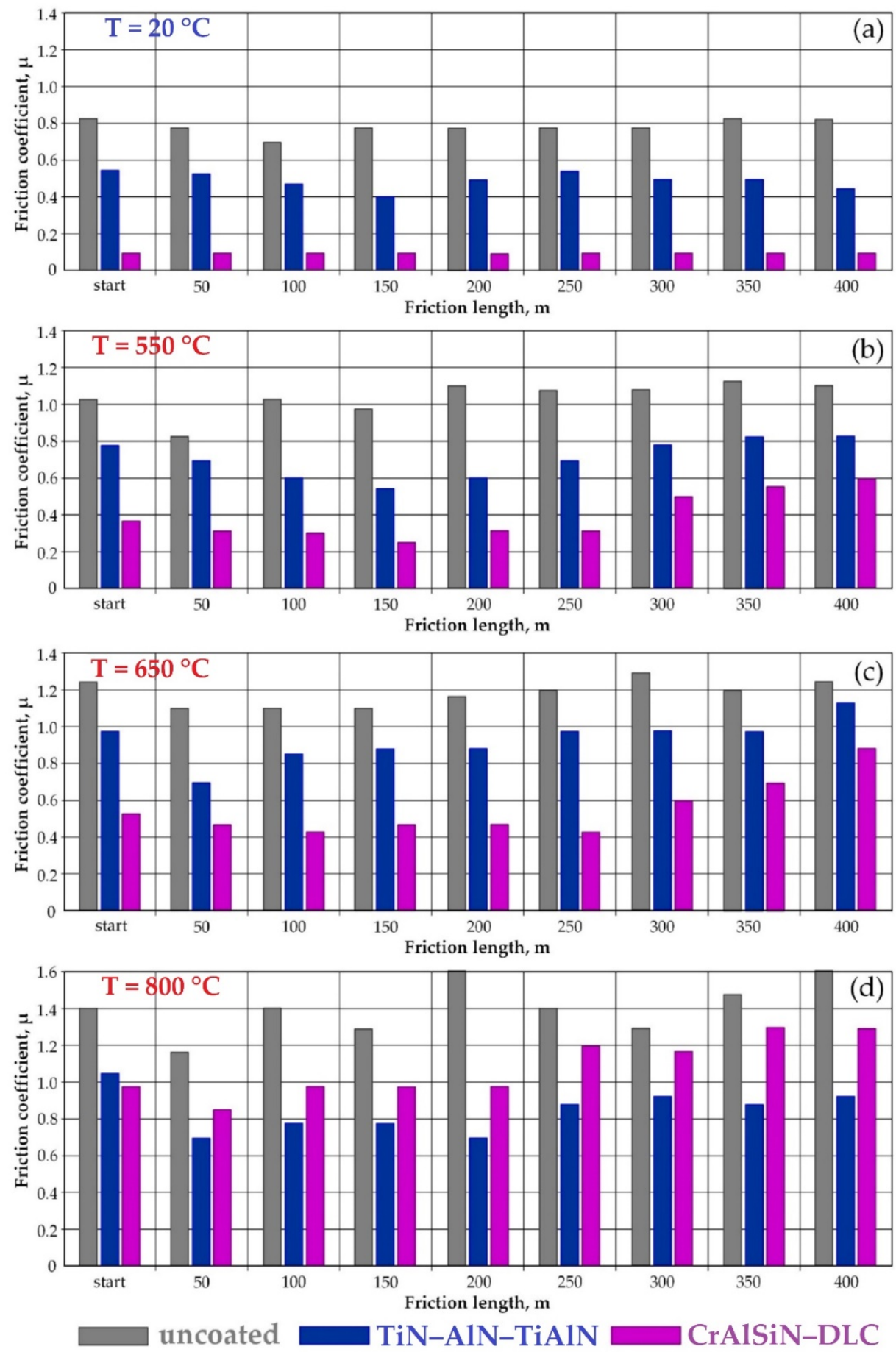

Figure 7. Dependences of the friction coefficient of the surface of hard-alloy specimens with different coatings on the length of the friction path with varying temperature test conditions: (a) $20{ }^{\circ} \mathrm{C}$; (b) $550{ }^{\circ} \mathrm{C}$; (c) $650{ }^{\circ} \mathrm{C}$; (d) $800{ }^{\circ} \mathrm{C}$.

\subsection{Cutting Capacity of Coated End Mills in Milling}

Figure 8 shows the experimentally obtained dependences of the wear of the flank face of ball end mills with different coatings on the machining time of the nickel alloy at cutting speeds of 150,200, and $250 \mathrm{~m} / \mathrm{min}$. The character of wear in all investigated speed modes had a classic character, such as the zones of running-in, steady-state, and critical wear that were traced. For an uncoated tool, the milling time until the flank reached the critical wear value was $43 \mathrm{~min}$ at a cutting speed of $150 \mathrm{~m} / \mathrm{min}, 35 \mathrm{~min}$ at $200 \mathrm{~m} / \mathrm{min}$, and $23 \mathrm{~min}$ at $250 \mathrm{~m} / \mathrm{min}$. Coating in all the cases affected the cutting ability of ball end mills, but at different cutting 
speeds; the effect of TiN-AlN-TiAlN and CrAlSiN-DLC coatings is noticeably different. For the TiN-AlN-TiAlN coating at cutting speeds of 150 and $200 \mathrm{~m} / \mathrm{min}$, the milling time until the critical wear value was reached increased slightly compared to the uncoated tool, by 1.2 times. The effect of the CrAlSiN-DLC coating was more significant; the milling time to critical wear increased by 1.5 and 1.4 times at cutting speeds of 150 and $200 \mathrm{~m} / \mathrm{min}$, respectively. The effect of the two coatings was completely reversed when tested at a cutting speed of $250 \mathrm{~m} / \mathrm{min}$. The CrAlSiN-DLC coating did not practically reduce the wear rate of the end mills; the cutting ability only increased by 1.1 times while the TiN-AlN-TiAlN coating increased the indicated indicator by 1.3 times.

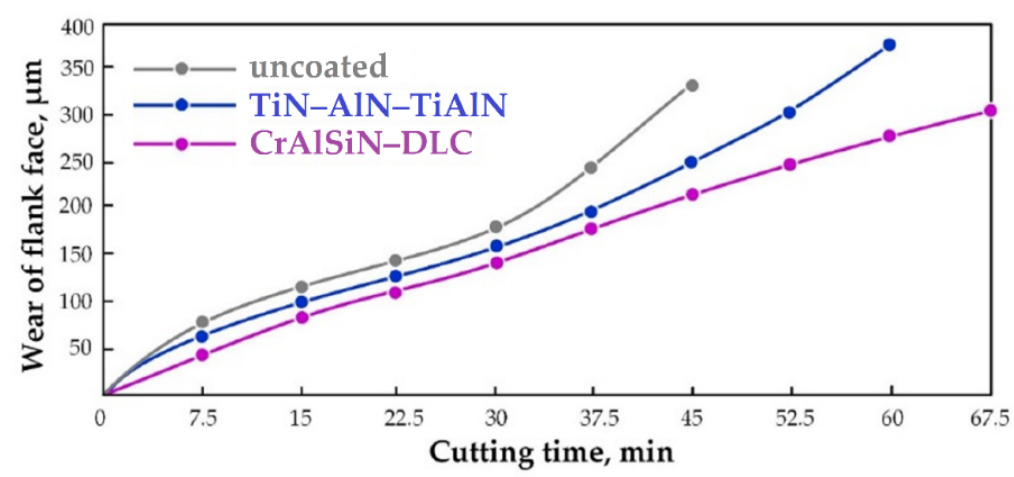

(a)

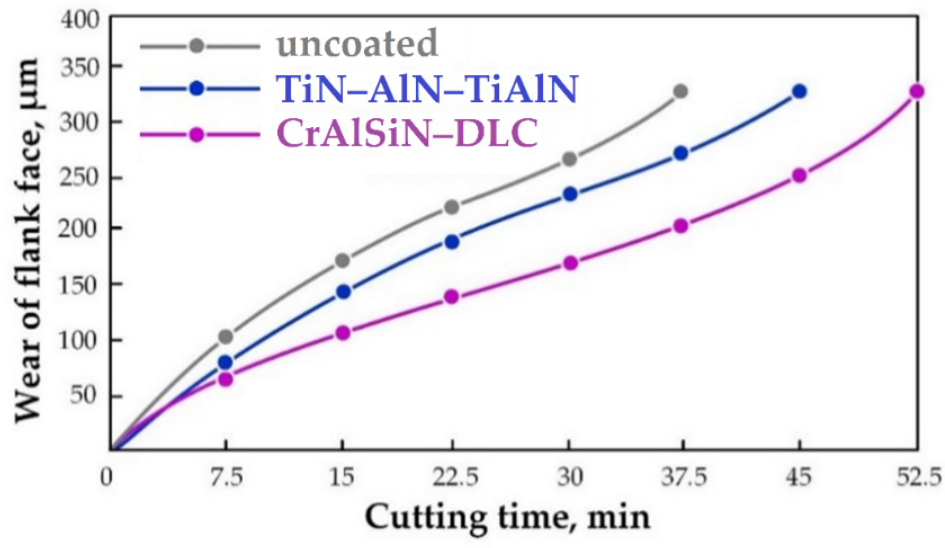

(b)

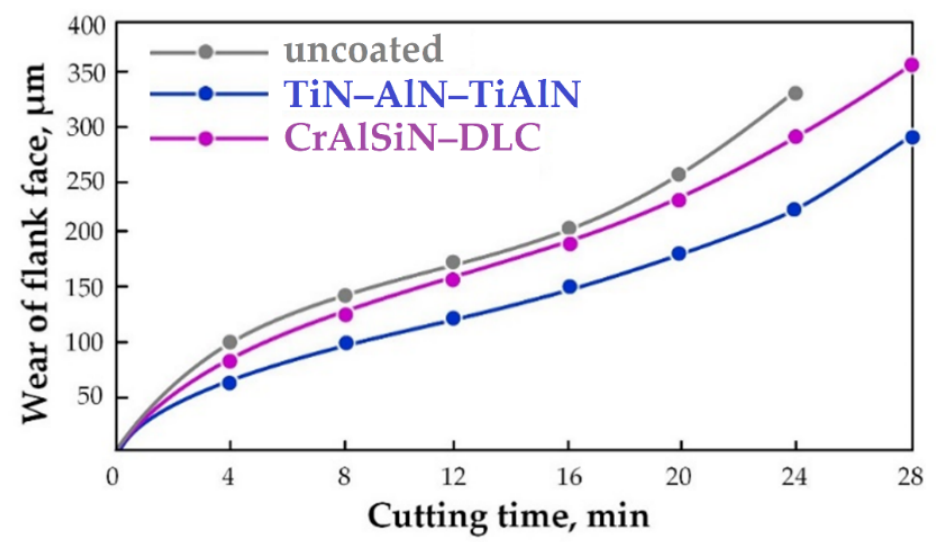

(c)

Figure 8. Dependences of the flank wear of ball end mills with different coatings on the machining time of the nickel alloy at different cutting speeds: (a) $150 \mathrm{~m} / \mathrm{min}$; (b) $200 \mathrm{~m} / \mathrm{min}$; (c) $250 \mathrm{~m} / \mathrm{min}$. 


\subsection{Cutting Zone Temperature Measured by Natural Thermocouple Method}

Figure 9 shows the data on the change in the average temperature at the contact pads of ball end mills in machining a nickel alloy at speeds of 150, 200, and $250 \mathrm{~m} / \mathrm{min}$. It can be seen that the CrAlSiN-DLC coating reduced the average temperature in the cutting zone by 60 and $65{ }^{\circ} \mathrm{C}$ degrees at cutting speeds of 150 and $200 \mathrm{~m} / \mathrm{min}$ and for uncoated end mills, this was 590 and $690^{\circ} \mathrm{C}$, respectively. The TiN-AlN-TiAlN coating reduced the temperature less significantly by 30 and $25^{\circ} \mathrm{C}$. When the tool was operated at a cutting speed of $250 \mathrm{~m} / \mathrm{min}$, the picture changes - the CrAlSiN-DLC coating did not practically change the level of temperature effect on the contact pads as compared to the uncoated tool while the TiN-AlN-TiAlN coating significantly reduced this indicator, from 875 to $790{ }^{\circ} \mathrm{C}$.

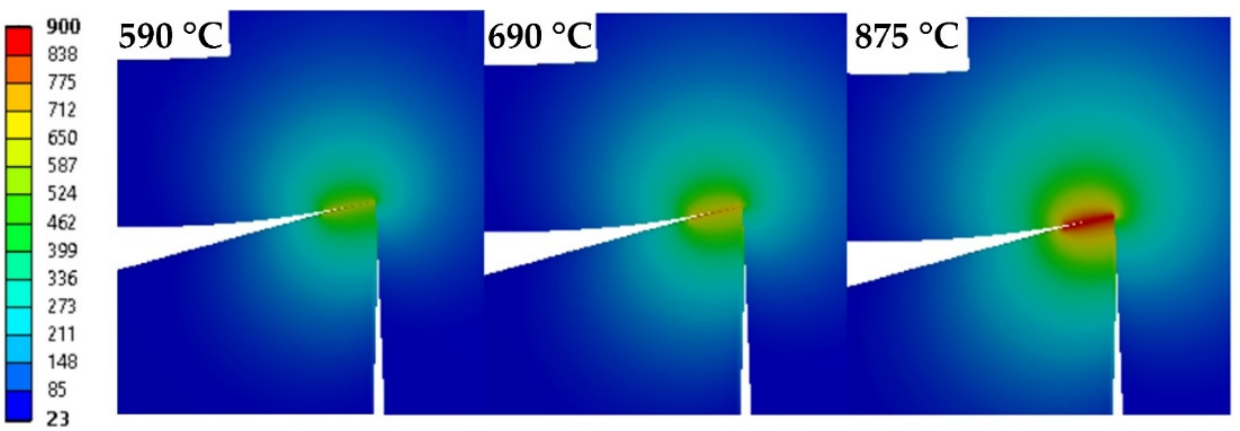

(a)
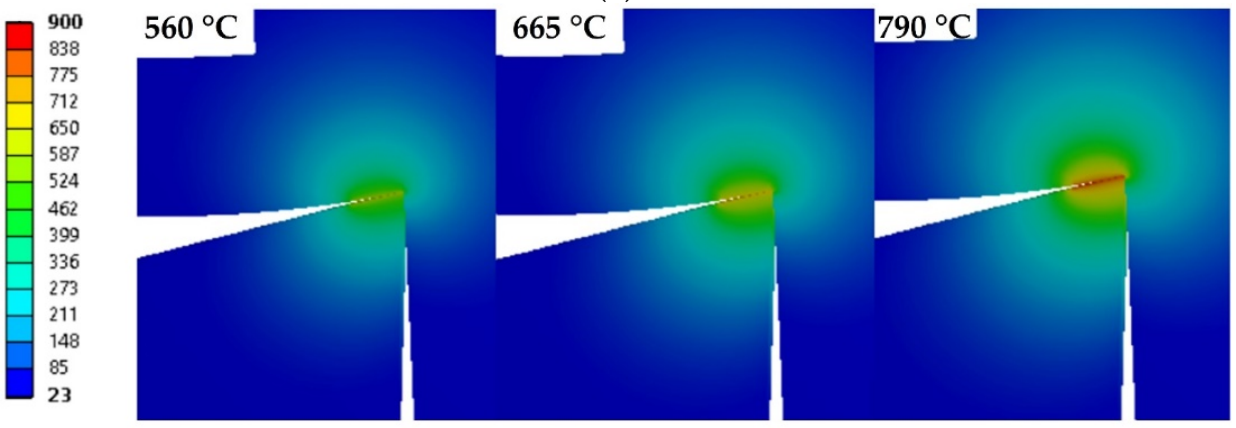

(b)
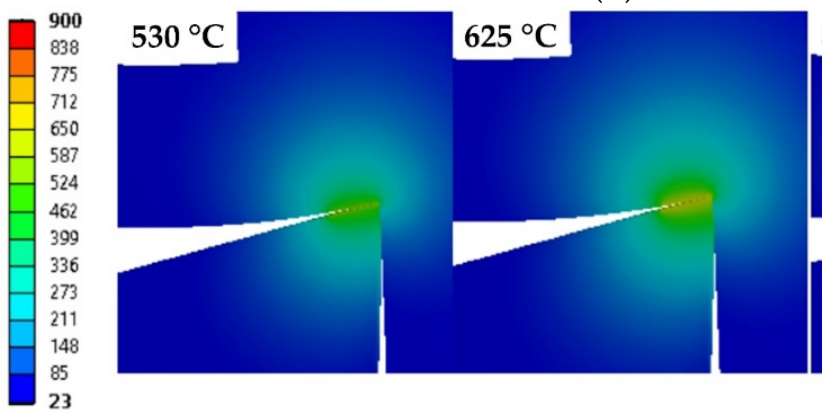

$870{ }^{\circ} \mathrm{C}$

(c)

Figure 9. Temperature change on pads of uncoated (a), TiN-AlN-TiAlN-coated (b), and CrAlSiNDLC-coated ball end mills (c) measured by natural thermocouple when machining nickel alloy at different cutting speeds and visualized by Deform software module; left to right: 150, 200, and $250 \mathrm{~m} / \mathrm{min}$.

\subsection{Surface Condition of Machined Part and End Mills}

It was found that in the entire speed range when testing uncoated ball end mills, the entire surface of the machined part had a large number of adhesions-tightly welded particles of the nickel alloy. In addition, a relatively dense layer of nickel alloy was found on the rake face of the end mills. At cutting speeds of 150 and $200 \mathrm{~m} / \mathrm{min}$, the amount of stuck material on the parts and the rake face of the tool was significantly reduced when 
using the CrAlSiN-DLC coating, and the TiN-AlN-TiAlN coating did not significantly affect the surface condition. Figure 10 shows 3D profilograms of the surface state of a machined workpiece made of nickel alloy after milling at a cutting speed of $150 \mathrm{~m} / \mathrm{min}$ with an uncoated tool and two coated ones. Similar results were observed when testing at $200 \mathrm{~m} / \mathrm{min}$. When tested at a cutting speed of $250 \mathrm{~m} / \mathrm{min}$, the effect of the CrAlSiN-DLC coating in reducing the amount of stuck material was minimal. Moreover, a relatively dense layer of the machined nickel alloy was formed on the rake face of the tool. On the other hand, the TiN-AlN-TiAlN coating at $250 \mathrm{~m} / \mathrm{min}$ markedly reduced the stuck material on the workpiece and protected the rake face of the end mills from sticking. Figure 11 shows SEM images of the state of the contact surfaces of end mills after 20 min of testing at a cutting speed of $250 \mathrm{~m} / \mathrm{min}$.
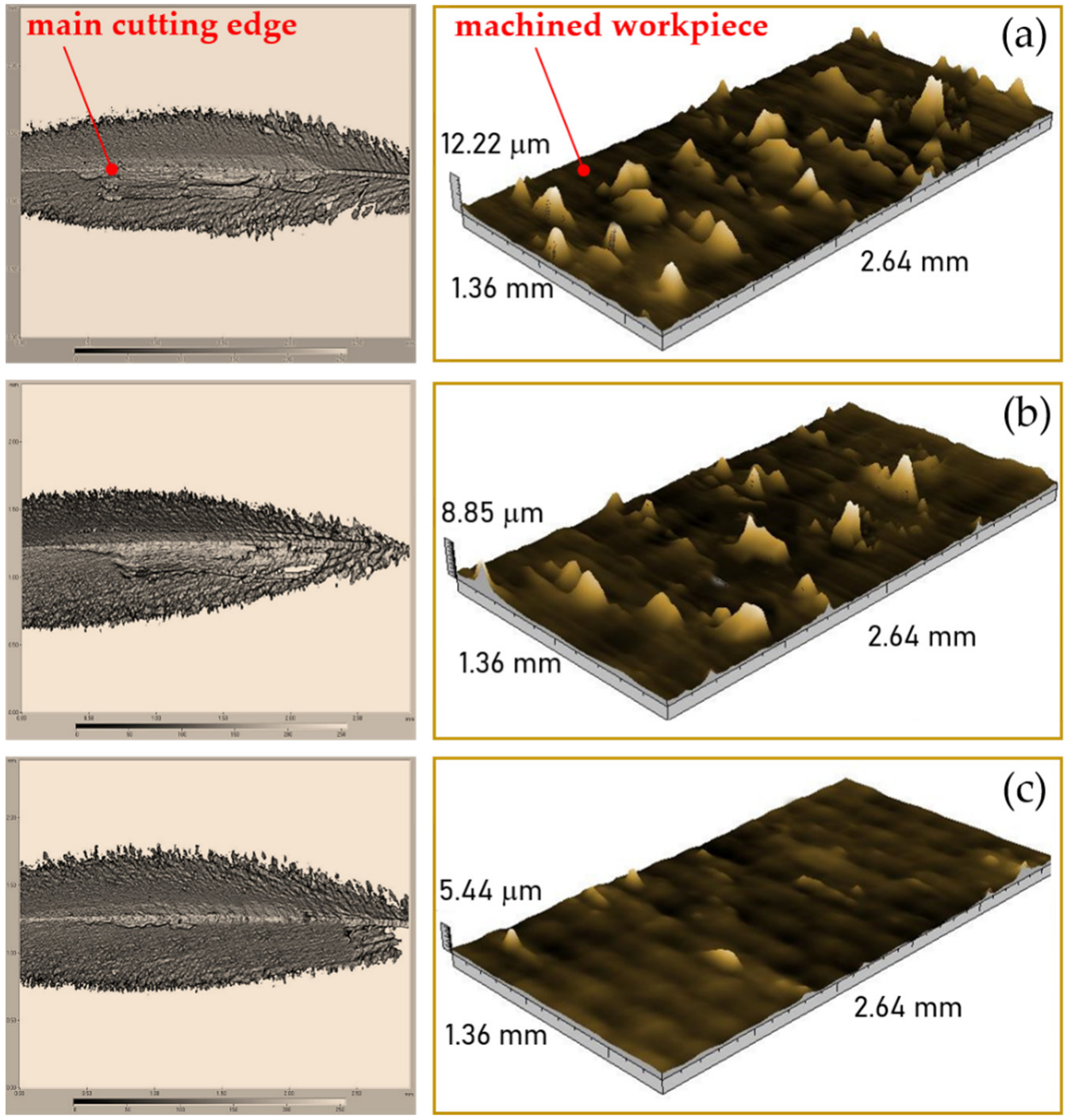

Figure 10. The condition of the main cutting edge of ball end mills and 3D profilograms of the surface condition of a machined nickel alloy workpiece after milling at a cutting speed of $150 \mathrm{~m} / \mathrm{min}$ with ball end mills with various coatings: (a) uncoated; (b) with TiN-AlN-TiAlN coating; (c) with CrAlSiN-DLC coating. 


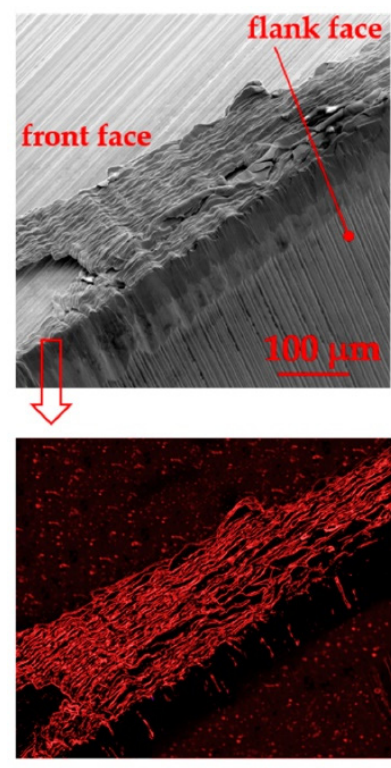

(a)
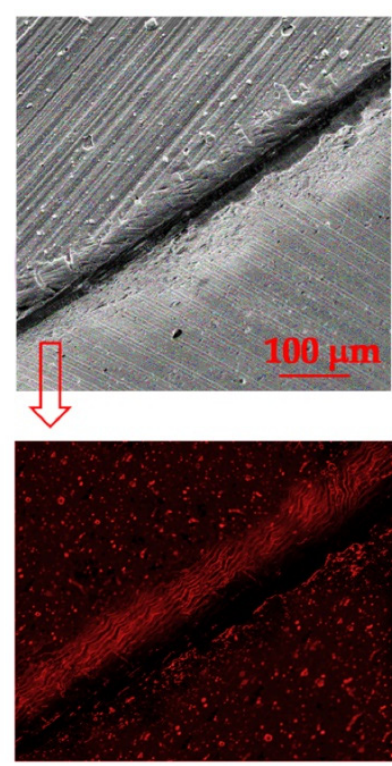

(b)

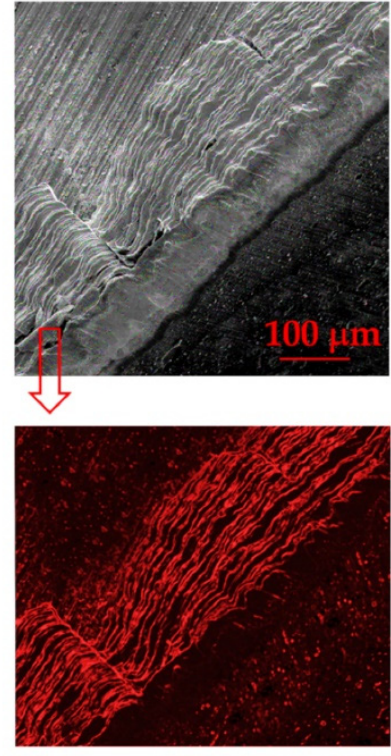

(c)

Figure 11. The condition of the working surfaces of ball end mills with different coatings and contrast SEM images of the distribution of nickel (particles in red) on the working surfaces of end mills when machining a nickel alloy at a cutting speed of $250 \mathrm{~m} / \mathrm{min}$ : (a) uncoated; (b) with TiN-AlN-TiAlN coating; (c) with CrAlSiN-DLC coating.

\section{Discussion}

The results obtained regarding the increase in the resistance of the cemented carbide with coatings to abrasion (Figure 6) demonstrate expected trends as the formed TiN-AlNTiAlN and CrAlSiN-DLC coatings significantly increase the microhardness of the contact areas of the specimens. Lower abrasion of the CrAlSiN-DLC coating over most of the test distance has a similar character because the resistance to abrasive wear is determined not only by the microhardness of the contacting surfaces but also mainly by the friction coefficient on the contact pads. Optical analysis of worn holes shows that the rotating sphere quickly wipes through both variants of the coatings under the study, but the CrAlSiN-DLC coating is able to restrain the development of a wear center for a longer time. The finding can be explained by the so-called "edge effect", which is when the coating remaining along the edges of the hole is capable of reducing the wear rate to a certain point. A similar mechanism was observed by various authors when studying the behavior of PVD coatings, in particular [70].

However, the data on resistance to abrasive wear are not sufficient in predicting the coating's behavior directly for cutting under the influence of increased temperature loads that are typical for milling nickel alloys. The results of tribological tests on a friction machine (Figure 7) were obtained at different levels of thermal impact on the contact zone of two counter bodies, involving a tool hard alloy and a processed nickel alloy, which are of great research interest. Figure 7a shows that nitride coatings are obviously and noticeably inferior to the DLC coating at room temperature, which was predictable when taking into account the experimental results previously obtained by the authors of the work in the study of the frictional behavior of various coatings in contact with a nickel alloy [71].

The results of tribological tests when exposed to high temperatures, such as 550, 650, and $800{ }^{\circ} \mathrm{C}$ (Figure $7 \mathrm{~b}-\mathrm{c}$ ), can explain the effectiveness of the CrAlSiN-DLC coating in terms of increasing the tool cutting ability during milling at cutting speeds of 150 and $200 \mathrm{~m} / \mathrm{min}$ (1.5 and 1.4 times). However, while milling at speeds of $250 \mathrm{~m} / \mathrm{min}$ (Figure 8 ) when elevated temperatures act on the cutting edge, the coating did not show any effect. For example, when analyzing the measured average temperatures of the contact pads of ball end mills with the CrAlSiN-DLC coating (Figure 9), it can be seen that they were of 
530,620 , and $870{ }^{\circ} \mathrm{C}$ at cutting speeds of 150,200 , and $250 \mathrm{~m} / \mathrm{min}$, respectively. As follows from authoritative works $[8-10,17]$, the prevailing wear mechanism is the adhesive in such temperature conditions, which occurs due to continuous and repetitive gripping processes (cold welding) of the workpiece material and the tool. An increase in temperature promotes an increase in the adhesion component of the friction coefficient, intensifies the gripping processes, and increases the gripping area of the contacting surfaces and the amount of heat released during friction. Thus, when the temperature in the contact zone of two materials rises, an increase in the contact surfaces' friction force and wear rate is expected. In this work, such conclusions were made for the machined material of an Inconel 718-type alloy, but the observed patterns are valid for a broad class of materials. The authors of [72] drew similar conclusions for machining AISI 316 L stainless steel.

The CrAlSiN-DLC coating is quite efficient in operating at temperatures up to $650^{\circ} \mathrm{C}$; although the coefficient of friction increases markedly, the contact pads are able to restrain the gripping processes. An increase in temperature to $800^{\circ} \mathrm{C}$ causes irreversible structural changes and loss of hardness of the DLC layer, and the friction conditions approach those of a cemented carbide. There is a slight decrease in the coefficient of friction, even at a temperature of $800^{\circ} \mathrm{C}$ (Figure 8), for the CrAlSiN-DLC coating, but this is definitely not enough to increase the tool cutting ability.

As long as the CrAlSiN-DLC coating exhibits a lower coefficient of friction at cutting speeds of 150 and $200 \mathrm{~m} / \mathrm{min}$, which corresponds to cutting temperatures of 530 and $620^{\circ} \mathrm{C}$, respectively, it contributes to the already described significant reduction in the intensification of adhesive gripping processes. The effect of the CrAlSiN-DLC coating at milling speeds of 150 and $200 \mathrm{~m} / \mathrm{min}$ and the average cutting temperatures corresponding to these conditions of about 530 and $625^{\circ} \mathrm{C}$ (Figure 9) can be considered significant as the milling time to critical wear increases by 1.5 and 1.4 times. Furthermore, it immediately affects the condition of the surfaces in contact. Under these conditions, there is minimal stuck material on the surface of the machined part and the working surfaces of ball end mills. As can be seen in Figure 8c, the cutting ability of ball end mills under such conditions increases only 1.1 times, which is insignificant.

The results of high-temperature tribological tests (Figure 7) correlate well with the results obtained when assessing the cutting ability of ball end mills and can explain the surface condition of the machined workpiece (Figure 10) and tool contact pads (Figure 11), which were observed at different speeds and temperature conditions.

The coefficient of friction on the contact surfaces significantly depends on the level of thermal exposure, predetermines the wear intensity of the cutting part of the ball end mill in machining nickel alloys, and affects the state of the machined surface of the part.

The data presented in Figure 9 at a cutting speed of $150 \mathrm{~m} / \mathrm{min}$ demonstrate a critical pattern involving higher temperature and friction coefficient on the working surfaces of ball end mills without coating and with the TiN-AlN-TiAlN coating contributing to intense sticking of the nickel alloy to the active part cutting edge and directly onto the machined surface of the part, significantly worsening its condition. Many authors, particularly in the review, noted increased adhesion of the nickel alloy to the carbide tool and workpiece when using nitride coatings at cutting speeds up to $150 \mathrm{~m} / \mathrm{min}$ [73]. In the case of the CrAlSiN-DLC coating formed on the working surfaces, lower temperatures and friction coefficients are observed in the cutting zone, and there are barely noticeable deposits on the cutting edge. In this case, the surface condition of the part is significantly improved.

The higher cutting temperatures that occur at high milling speeds $(250 \mathrm{~m} / \mathrm{min})$ and the increased coefficient of friction on the contact surfaces observed for ball end mills without coating and with CrAlSiN-DLC coating contribute to the sticking ("spreading") of the nickel alloy on the cutting edge and flank face of the tool (Figure 10). In addition, the presented SEM images of the distribution of nickel (particles of red color) on the tool's working surfaces make it possible to visually evaluate the differences between cutters without coating and with two coating options. 
The TiN-AlN-TiAlN coating showed noticeably lower values of the coefficient of friction and a higher cutting ability at a cutting speed of $250 \mathrm{~m} / \mathrm{min}$ contrarily at a temperature of about $800{ }^{\circ} \mathrm{C}$ (although the coating showed an insignificant effect at cutting speeds of 150 and $200 \mathrm{~m} / \mathrm{min}$ ). That can be explained by the ability of such compounds to form so-called secondary structures [74-78]. The TiAlN compound tends to oxidize and form relatively stable surface alumina oxide films. In machining at high cutting speeds, alumina films formed on the surface can limit the interaction of the underlying coating layers with the chip and workpiece material.

It can be concluded that as long as the CrAlSiN-DLC coating exhibits a lower coefficient of friction at cutting speeds of 150 and $200 \mathrm{~m} / \mathrm{min}$, which correspond to cutting temperatures of 530 and $620^{\circ} \mathrm{C}$, respectively, the coating contributes to the already described significant reduction in the intensification of adhesive gripping processes. Furthermore, it immediately affects the condition of the surfaces in contact. Under these conditions, there is minimal stuck material on the surface of the machined part and the working surfaces of ball end mills. Negative structural changes occurring in the CrAlSiN-DLC coating at a cutting speed of $250 \mathrm{~m} / \mathrm{min}$ (at a cutting temperature of $870^{\circ} \mathrm{C}$ ) do not protect the contact surfaces, and the intensity of adhesion of the nickel alloy to the workpiece and the cutting tool is very high and similar to that observed for cutters without coating. On the contrary, the TiN-AlNTiAlN coating, at cutting speeds of 150 and $200 \mathrm{~m} / \mathrm{min}$, does not have a noticeable effect on the formation of adhesions, but the intensity of nickel alloy adhesion to the workpiece and the working platforms of the end mill is significantly reduced at $250 \mathrm{~m} / \mathrm{min}$. This finding can be explained by the formation of the above-mentioned secondary structures, such as alumina-based films, which reduce the adhesive gripping.

\section{Conclusions}

The novelty of the current study lies in:

- The research of the prospective architecture of the CrAlSiN-DLC coating (a-C:H:Si) deposed to the cemented carbide tool that had never been proposed before for machining nickel alloys.

- The comparison of experimental results with the behavior of the sharply new-designed multilayer TiN-AlN-TiAlN coating deposed to the cemented carbide ball end mill.

- The focus on the conditions of the cutting edge under the estimated thermal loads (up to $\sim 850{ }^{\circ} \mathrm{C}$ ) and quality of the machined part surface after milling in a wide speed range.

The practical significance of the work lies in:

- Conducting experimental research in a condition close to the conditions of real production, which can have a possible short-term impact on the industry.

- Formulating a real technological solution on the usage of a newly designed coating deposed to the commercial cemented carbide ball end mill with the proposed cutting conditions for convex surfaces of the aircraft part made of nickel alloy that can be immediately applied in the condition of the industrial production.

The main differences between this work and similar works are:

- The development of experimental work in conditions close to those of real production, which is of fundamental importance for the industry.

- Using a type of prospective coating never before proposed for the machining of difficult-to-machine alloys.

- The orientation of the experimental part of the work, specifically on the behavior of the main cutting edge under conditions of thermal loads.

- A comparison of the results obtained using the prospective architecture of the CrAlSiNDLC coating with a sharply new multi-layer coating, which is one of the most promising in modern tool production.

- The study of the operational behavior of coatings on the example of a complex profile tool. 
The experimental studies showed that the temperature near the cutting edge is the parameter that limits the cutting ability of diamond-like carbon a-C:H:Si-coated ball end mills in cutting nickel alloys of the Inconel 718 type to a greater extent (in the conditions of dry milling). Studies demonstrate that the cutting ability of ball end mills at certain cutting temperatures correlates well with the tool material in the process of tribological tests when heated to temperatures of a similar level. Studying the frictional behavior of the cemented carbide surface layer with various coatings on a friction machine under high-temperature heating conditions is a suitable tool for express testing and for making decisions on the advisability of further testing the effectiveness of the coating on the machine when cutting nickel alloys.

Forming DLC based on a-C:H:Si coating with a pre-formed nitride CrAlSiN sublayer on the surface of cemented carbide ball end mills that are intended for processing heatresistant alloys of the Inconel 718 type can significantly reduce the frictional interaction on the contact surfaces, and can thereby reduce the amount of heat generated by friction and reduce the temperature near the cutting edge, according to the technology described in this work. As a result, the CrAlSiN-DLC coating can be considered effective for solving the technological problem of increasing the cutting ability of the tool as well as for improving the condition of the machined surface and reducing the amount of stuck material that significantly degrades the quality of the machined part and intensifies the wear of the tool contact pads. However, it should be emphasized that the above is true only for conditions when the temperature effect on the surface layer of samples with CrA1SiN-DLC coating does not exceed $650{ }^{\circ} \mathrm{C}$. This requirement is matched by the temperature mode, which takes place at cutting speeds of 150 and $200 \mathrm{~m} / \mathrm{min}$ for the chosen milling conditions. Under such conditions, the milling time within which the flank face reaches the critical wear value for end mills with the CrAlSiN-DLC coating is more than 67 and $50 \mathrm{~min}$, respectively, which is 1.4-1.5 times longer than that of an uncoated tool and about 1.3 times longer than with a TiN-AlN-TiAlN coating. At the same time, the operation of end mills with the CrAlSiN-DLC coating is characterized by a minimum amount of adhesion on the machined part compared to the specified nitride coating.

Structural changes occur in CrAlSiN-DLC coatings and are accompanied by a loss of properties, and they are no longer able to provide any noticeable effect at higher cutting temperatures, in particular, at temperatures of the order of $800{ }^{\circ} \mathrm{C}$ (for the conditions selected in the work, such temperatures corresponded to a cutting speed of $250 \mathrm{~m} / \mathrm{min}$ ). At the same time, the TiN-AlN-TiAlN coating showed better cutting ability, presumably due to the formation of stable alumina-based compounds, which reduce the adhesive gripping.

Further development of research regarding solving the problem of increasing the cutting ability of ball end mills in machining nickel alloys should involve finding opportunities to maintain a reduced level of frictional interaction (coefficient of friction) in areas of higher temperatures. Therefore, it is necessary to consider various approaches associated with doping with DLC elements capable of forming wear-resistant protective compounds during high-temperature heating to the end. In addition, it is necessary to optimize the DLC architecture and pre-form the nitride- or oxide-based sublayers. Such layers should have increased thermodynamic stability and provide the necessary strength of the adhesion bond between the DLC and the carbide base at the same time.

Author Contributions: Conceptualization, S.N.G.; methodology, M.S.M. and M.A.V.; validation, S.V.F., M.M. and A.G.; formal analysis, S.V.F., M.M. and A.G.; investigation, M.S.M., M.A.V., M.M. and A.G.; resources, S.V.F.; data curation, S.V.F. and A.A.O.; writing-original draft preparation, M.S.M.; writing-review and editing, M.A.V.; visualization, M.A.V. and A.A.O.; supervision, S.N.G.; project administration, S.N.G. All authors have read and agreed to the published version of the manuscript.

Funding: This research was funded by the state assignment of the Ministry of Science and Higher Education of the Russian Federation, Project No. 0707-2020-0025.

Institutional Review Board Statement: Not applicable.

Informed Consent Statement: Not applicable. 
Data Availability Statement: Data are available in a publicly accessible repository.

Conflicts of Interest: The authors declare no conflict of interest.

\section{References}

1. Kumar, A.; Ensha, S.; Irvin, J.F.; Quinn, J. Liquid Metal Corrosion Fatigue (LMCF) Failure of Aircraft Engine Turbine Blades. J. Fail. Anal. Prev. 2018, 18, 939-947. [CrossRef]

2. McClung, R.C.; Bhamidipati, V. An investigation of small-crack effects in various aircraft engine rotor materials. Mater. High Temp. 2016, 33, 452-464. [CrossRef]

3. Sahoo, B.; Panigrahi, S.K.; Satpathy, R.K. Creep Life Degradation and Microstructure Degeneration in a Low-Pressure Turbine Blade of a Military Aircraft Engine. J. Fail. Anal. Prev. 2017, 17, 529-538. [CrossRef]

4. Volkov, A.M.; Karyagin, D.A.; Letnikov, M.N.; Bakradze, M.M.; Perevozov, A.S. Specifics of Producing Disk Blanks for Gas-Turbine Engines Using Granules of Super Heat-Resistant Nickel Alloys. Metallurgist 2020, 64, 362-369. [CrossRef]

5. Martínez, S.; Ortega, N.; Celentano, D.; Sánchez Egea, A.J.; Ukar, E.; Lamikiz, A. Analysis of the part distortions for Inconel 718 SLM: A case study on the NIST test artifact. Materials 2020, 13, 5087. [CrossRef] [PubMed]

6. Lee, W.-S.; Lin, C.-F.; Chen, T.-H.; Chen, H.-W. Dynamic Impact Response of Inconel 718 Alloy under Low and High Temperatures. Mater. Trans. 2011, 52, 1734-1740. [CrossRef]

7. Grzesik, W.; Nieslony, P.; Laskowski, P. Determination of Material Constitutive Laws for Inconel 718 Superalloy Under Different Strain Rates and Working Temperatures. J. Mater. Eng. Perform. 2017, 26, 5705-5714. [CrossRef]

8. Vereschaka, A.A.; Grigoriev, S.N.; Vereschaka, A.S.; Popov, A.Y.; Batako, A.D. Nano-scale multilayered composite coatings for cutting tools operating under heavy cutting conditions. Procedia CIRP 2014, 14, 239-244. [CrossRef]

9. Grigoriev, S.N.; Gurin, V.D.; Volosova, M.A.; Cherkasova, N.Y. Development of residual cutting tool life prediction algorithm by processing on CNC machine tool. Materwiss. Werksttech. 2013, 44, 790-796. [CrossRef]

10. Moufki, A.; Le Coz, G.; Dudzinski, D. End-milling of Inconel 718 Superalloy-An Analytical Modelling. Procedia CIRP 2017, 58, 358-363. [CrossRef]

11. Pérez-Ruiz, J.D.; López de Lacalle, L.N.; Urbikain, G.; Pereira, O.; Martínez, S.; Jorge, B. On the relationship between cutting forces and anisotropy features in the milling of LPBF Inconel 718 for near net shape parts. Int. J. Mach. Tools Manuf. 2021, 170, 103801. [CrossRef]

12. Wang, B.; Liu, Z. Influences of tool structure, tool material and tool wear on machined surface integrity during turning and milling of titanium and nickel alloys: A review. Int. J. Adv. Manuf. Technol. 2018, 98, 1925-1975. [CrossRef]

13. Ulutan, D.; Özel, T. Machining induced surface integrity in titanium and nickel alloys: A review. Int. J. Mach. Tools Manuf. 2011, 51, 250-280. [CrossRef]

14. Wang, J.T.; Zhang, D.H.; Wu, B.H.; Luo, M. Residual Stresses Analysis in Ball end Milling of Nickel-Based Superalloy Inconel 718. Mater. Res. 2017, 20, 1681-1689. [CrossRef]

15. Denkena, B.; Pape, O.; Mucke, A. Process design for 5-axis ball end milling using a real-time capable dynamic material removal simulation. Prod. Eng. 2021, 15, 89-95. [CrossRef]

16. Burek, J.; Plodzien, M.; Zylka, C.; Sulkowicz, P. High-performance end milling of aluminum alloy: Influence of different serrated cutting-edge tool shapes on the cutting force. Adv. Prod. Eng. Manag. 2019, 14, 494-506. [CrossRef]

17. Lanz, R.W.; Melkote, S.N.; Kotnis, M. Effect of process parameters and tool shape on the machinability of a particulate filledpolymer composite material for rapid tooling. Mach. Sci. Technol. 2001, 5, 2017-2237. [CrossRef]

18. Zhu, D.; Zhang, X.; Ding, H. Tool Wear Characteristics in Machining of Nickel-based superalloys. Int. J. Mac. Tools Manuf. 2013, 64, 60-77. [CrossRef]

19. Kuzin, V.V.; Grigoriev, S.N.; Volosova, M.A. The role of the thermal factor in the wear mechanism of ceramic tools: Part 1. Macrolevel. J. Frict. Wear 2014, 35, 505-510. [CrossRef]

20. Zheng, G.; Zhao, J.; Zhou, Y.; Li, A.; Cui, X.; Tian, X. Performance of graded nano-composite ceramic tools in ultra-high-speed milling of Inconel 718. Int. J. Adv. Manuf. Technol. 2013, 67, 2799-2810. [CrossRef]

21. Lu, X.; Wang, H.; Jia, Z.; Feng, Y.; Liang, S.Y. Coupled thermal and mechanical analyses of micro-milling Inconel 718. Proc. Inst. Mech. Eng. Part B J. Eng. Manuf. 2018, 233, 1112-1126. [CrossRef]

22. Grigoriev, S.N.; Vereschaka, A.A.; Vereschaka, A.S.; Kutin, A.A. Cutting tools made of layered composite ceramics with nano-scale multilayered coatings. Proc. CIRP 2012, 1, 301-306. [CrossRef]

23. Bhatt, A.; Attia, H.; Vargas, R.; Thomson, V. Wear mechanisms of WC coated and uncoated tools in finish turning of Inconel 718. Tribol. Int. 2010, 43, 1113-1121. [CrossRef]

24. Grigoriev, S.N.; Sinopalnikov, V.A.; Tereshin, M.V.; Gurin, V.D. Control of parameters of the cutting process on the basis of diagnostics of the machine tool and workpiece. Meas. Tech. 2012, 55, 555-558. [CrossRef]

25. Ezugwu, E.O.; Wang, Z.M.; Machado, A.R. The machinability of nickel-based alloys: A review. J. Mater. Process. Technol. 1998, 86, 1-16. [CrossRef]

26. Chen, X.Q.; Li, H.Z. Development of a tool wear observer model for online tool condition monitoring and control in machining nickelbased alloys. Int. J. Adv. Manuf. Technol. 2009, 45, 786-800. [CrossRef] 
27. Vereschaka, A.; Tabakov, V.; Grigoriev, S.; Sitnikov, N.; Andreev, N.; Milovich, F. Investigation of wear and diffusion processes on rake faces of carbide inserts with Ti-TiN-(Ti,Al,Si)N composite nanostructured coating. Wear 2018, 416, 72-80. [CrossRef]

28. Kitagawa, T.; Kubo, A.; Maekawa, K. Temperature and wear of cutting tools in high-speed machining of Inconel 718 and Ti-6Al-6V-2Sn. Wear 1997, 202, 142-148. [CrossRef]

29. Hao, Z.; Gao, D.; Fan, Y.; Han, R. New observations on tool wear mechanism in dry machining Inconel 718. Int. J. Mach. Tools Manuf. 2011, 51, 973-979. [CrossRef]

30. Vereschaka, A.S.; Grigoriev, S.N.; Tabakov, V.P.; Sotova, E.S.; Vereschaka, A.A.; Kulikov, M.Y. Improving the efficiency of the cutting tool made of ceramic when machining hardened steel by applying nano-dispersed multi-layered coatings. Key Eng. Mater. 2014, 581, 68-73. [CrossRef]

31. Grguras, D.; Kern, M.; Pusavec, F. Suitability of the full body ceramic end milling tools for high-speed machining of nickel based alloy Inconel 718. Procedia CIRP 2018, 77, 630-633.

32. Volosova, M.A.; Grigor'ev, S.N.; Kuzin, V.V. Effect of Tinaium Nitride Coatings on Stress Structural Inhomogeneity in OxideCarbide Ceramic. Part 2. Concentrated Force Action. Refract. Ind. Ceram. 2015, 55, 487-491. [CrossRef]

33. Fernández-Lucio, P.; Pereira Neto, O.; Gómez-Escudero, G.; Amigo Fuertes, F.J.; Fernández Valdivielso, A.; López de Lacalle Marcaide, L.N. Roughing Milling with Ceramic Tools in Comparison with Sintered Carbide on Nickel-Based Alloys. Coatings 2021, 11, 734. [CrossRef]

34. Molaiekiya, F.; Stolf, P.; Paiva, J.M.; Bose, B.; Goldsmith, J.; Gey, C.; Engin, S.; Fox-Rabinovich, G.; Veldhuis, S.C. Influence of process parameters on the cutting performance of SiAlON ceramic tools during high-speed dry face milling of hardened Inconel 718. Int. J. Adv. Manuf. Technol. 2019, 105, 1083-1098. [CrossRef]

35. Grigoriev, S.; Peretyagin, P.; Smirnov, A.; Solis, W.; Diaz, L.A.; Fernandez, A.; Torrecillas, R. Effect of graphene addition on the mechanical and electrical properties of $\mathrm{Al}_{2} \mathrm{O}_{3}-\mathrm{SiCw}$ ceramics. J. Eur. Ceram. Soc. 2017, 37, 2473-2479. [CrossRef]

36. Akmal, M.; Layegh, K.E.; Lazoglu, I.; Akgün, A.; Yavaş, C. Friction Coefficients on Surface Finish of AlTiN Coated Tools in the Milling of Ti6Al4V. Procedia CIRP 2017, 58, 596-600. [CrossRef]

37. Vereschaka, A.A.; Volosova, M.A.; Grigoriev, S.N.; Vereschaka, A.S. Development of wear-resistant complex for high-speed steel tool when using process of combined cathodic vacuum arc deposition. Procedia CIRP 2013, 9, 8-12. [CrossRef]

38. Young, H.T.; Mathew, P.; Oxley, P.L.B. Predicting Cutting Forces in Face Milling. Int. J. Mach. Tools Manuf. 1994, 34, 771-783. [CrossRef]

39. Oxley, P.L.B. Development and application of a predictive machining theory. Mach. Sci. Technol. 1998, 2, 165-189. [CrossRef]

40. Aihua, L.; Jianxin, D.; Haibing, C.; Yangyang, C.; Jun, Z. Friction and wear properties of TiN, TiAlN, AlTiN and CrAlN PVD nitride coatings. Int. J. Refract. Hard Met. 2012, 31, 82-88. [CrossRef]

41. Sun, S.; Brandt, M.; Dargusch, M.S. Thermally enhanced machining of hard-to-machine materials-A review. Int. J. Mach. Tools Manuf. 2010, 50, 663-680. [CrossRef]

42. Sobol, O.V.; Andreev, A.A.; Grigoriev, S.N.; Gorban, V.F.; Volosova, M.A.; Aleshin, S.V.; Stolbovoi, V.A. Effect of high-voltage pulses on the structure and properties of titanium nitride vacuum-arc coatings. Met. Sci. Heat Treat. 2012, 54, 195-203. [CrossRef]

43. Durmaz, Y.M.; Yildiz, F. The wear performance of carbide tools coated with TiAlSiN, AlCrN and TiAlN ceramic films in intelligent machining process. Ceram. Int. 2019, 45, 3839-3848. [CrossRef]

44. Vereschaka, A.; Tabakov, V.; Grigoriev, S.; Aksenenko, A.; Sitnikov, N.; Oganyan, G.; Seleznev, A.; Shevchenko, S. Effect of adhesion and the wear-resistant layer thickness ratio on mechanical and performance properties of $\mathrm{ZrN}-(\mathrm{Zr}, \mathrm{Al}, \mathrm{Si}) \mathrm{N}$ coatings. Surf. Coat. Technol. 2019, 357, 218-234. [CrossRef]

45. Volosova, M.; Grigoriev, S.; Metel, A.; Shein, A. The role of thin-film vacuum-plasma coatings and their influence on the efficiency of ceramic cutting inserts. Coatings 2018, 8, 287. [CrossRef]

46. Robertson, J. Diamond-like amorphous carbon. Mater. Sci. Eng. R Rep. 2002, 37, 129-281. [CrossRef]

47. Hainsworth, S.V.; Uhure, N.J. Diamond like carbon coatings for tribology: Production techniques, characterisation methods and applications. Int. Mater. Rev. 2007, 52, 153-174. [CrossRef]

48. Martinez-Martinez, D.; De Hosson, J. On the deposition and properties of DLC protective coatings on elastomers: A critical review. Surf. Coat. Technol. 2014, 258, 677-690. [CrossRef]

49. Wei, C.; Yang, J.-F. A finite element analysis of the effects of residual stress, substrate roughness and non-uniform stress distribution on the mechanical properties of diamond-like carbon films. Diam. Relat. Mater. 2011, 20, 839-844. [CrossRef]

50. Aijaz, A.; Ferreira, F.; Oliveira, J.; Kubart, T. Mechanical properties of hydrogen free diamond-like carbon thin films deposited by high power impulse magnetron sputtering with Ne. Coatings 2018, 8, 385. [CrossRef]

51. Grigoriev, S.N.; Volosova, M.A.; Fedorov, S.V.; Mosyanov, M. Influence of DLC Coatings Deposited by PECVD Technology on the Wear Resistance of Carbide End Mills and Surface Roughness of AlCuMg 2 and 41Cr4 Workpieces. Coatings 2020, 10, 1038. [CrossRef]

52. Lubwama, M.; Corcoran, B.; McDonnell, K.A.; Dowling, D. Flexibility and frictional behaviour of DLC and Si-DLC films deposited on nitrile rubber. Surf. Coat. Technol. 2014, 239, 84-94. [CrossRef]

53. Podgursky, V.; Alamgir, A.; Yashin, M.; Jõgiaas, T.; Viljus, M.; Raadik, T.; Danilson, M.; Sergejev, F.; Lümkemann, A.; Kluson, J.; et al. High-Temperature Tribological Performance of $\mathrm{Al}_{2} \mathrm{O}_{3} / \mathrm{a}-\mathrm{C}: \mathrm{H}: \mathrm{Si}$ Coating in Ambient Air. Coatings 2021, 11, 495. [CrossRef]

54. Wu, Y.; Li, H.; Ji, L.; Ye, Y.; Chen, J.; Zhou, H. Vacuum tribological properties of a-C:H film in relation to internal stress and applied load. Tribol. Int. 2014, 71, 82-87. [CrossRef] 
55. Nakazawa, H.; Kamata, R.; Miura, S.; Okuno, S. Effects of frequency of pulsed substrate bias on structure and properties of silicon-doped diamond-like carbon films by plasma deposition. Thin Solid Film. 2015, 574, 93-98. [CrossRef]

56. Zou, C.W.; Wang, H.J.; Feng, L.; Xue, S.W. Effects of $\mathrm{Cr}$ concentrations on the microstructure, hardness, and temperaturedependent tribological properties of Cr-DLC coatings. Appl. Surf. Sci. 2013, 286, 137-141. [CrossRef]

57. GOST 5632-2014; Stainless Steels and Corrosion Resisting, Heat-Resisting and Creep Resisting Alloys. Grades. National Standard of the Russian Federation: Moscow, Russia, 2014.

58. Grigoriev, S.N.; Volosova, M.A.; Vereschaka, A.A.; Sitnikov, N.N.; Milovich, F. Properties of (Cr,Al,Si)N-(DLC-Si) composite coatings deposited on a cutting ceramic substrate. Ceram. Int. 2020, 46, 18241-18255. [CrossRef]

59. Jeon, Y.; Park, Y.S.; Kim, H.J.; Hong, B.; Choi, W.S. Tribological properties of ultrathin DLC films with and without metal interlayers. J. Korean Phys. Soc. 2007, 51, 1124-1128. [CrossRef]

60. Grigoriev, S.N.; Melnik, Y.A.; Metel, A.S.; Panin, V.V.; Prudnikov, V.V. A compact vapor source of conductive target material sputtered by 3-keV ions at 0.05-Pa pressure. Instrum. Exp. Tech. 2009, 52, 731-737. [CrossRef]

61. Metel, A.; Grigoriev, S.; Melnik, Y.; Panin, V.; Prudnikov, V. Cutting tools nitriding in plasma produced by a fast neutral molecule beam. Jpn. J. Appl. Phys. 2011, 50, 08JG04. [CrossRef]

62. Grigoriev, S.; Melnik, Y.; Metel, A. Broad fast neutral molecule beam sources for industrial scale beam-assisted deposition. Surf. Coat. Technol. 2002, 156, 44-49. [CrossRef]

63. Grigoriev, S.N.; Melnik, Y.A.; Metel, A.S.; Panin, V.V. Broad beam source of fast atoms produced as a result of charge exchange collisions of ions accelerated between two plasmas. Instrum. Exp. Tech. 2009, 52, 602. [CrossRef]

64. Metel, A.; Bolbukov, V.; Volosova, M.; Grigoriev, S.; Melnik, Y. Source of metal atoms and fast gas molecules for coating deposition on complex shaped dielectric products. Surf. Coat. Technol. 2013, 225, 34-39. [CrossRef]

65. Liu, Y.C.; Zhang, H.J.; Guo, Q.Y.; Zhou, X.S.; Ma, Z.Q.; Huang, Y.; Li, H.J. Microstructure evolution of Inconel 718 superalloy during hot working and its recent development tendency. Acta Met. Sin. 2018, 54, 1653-1664.

66. Kus, A.; Isik, Y.; Cakir, M.C.; Coşkun, S.; Özdemir, K. Thermocouple and Infrared Sensor-Based Measurement of Temperature Distribution in Metal Cutting. Sensors 2015, 15, 1274-1291. [CrossRef]

67. Grigoriev, S.N.; Kozochkin, M.P.; Sabirov, F.S.; Kutin, A.A. Diagnostic Systems as Basis for Technological Improvement. Proc. CIRP 2012, 1, 599-604. [CrossRef]

68. Abukhshim, N.A.; Mativenga, P.T.; Sheikh, M.A. Heat generation and temperature prediction in metal cutting: A review and implications for high-speed machining. Int. J. Mach. Tools Manuf. 2006, 46, 782-800. [CrossRef]

69. Yujing, S.; Jie, S.; Jianfeng, L.; Qingchun, X. An experimental investigation of the influence of cutting parameters on cutting temperature in milling Ti6AI4V by applying semi-artificial thermocouple. Int. J. Adv. Manuf. Technol. 2014, 70, 765-773.

70. Mo, J.L.; Zhu, M.H.; Leyland, A.; Matthews, A. Impact wear and abrasion resistance of CrN, AlCrN and AlTiN PVD coatings Surf. Coat. Technol. 2013, 215, 170-177. [CrossRef]

71. Volosova, M.A.; Fedorov, S.V.; Lyakhovetskiy, M.A.; Mustafaev, E.S.; Melnik, Y.A. Effect of PACVD deposition of nitride and Si-containing amorphous hydrogenated carbon films on the tribological characteristics of SiAlON ceramics. In Proceedings of the Nanoengineering: Fabrication, Properties, Optics, Thin Films, and Devices XVIII, San Diego, CA, USA, 1 August 2021.

72. Parthasarathi, N.L.; Borah, U.; Albert, S.K. Effect of temperature on sliding wear of AISI 316 L(N) stainless steel—Analysis of measured wear and surface roughness of wear tracks. Mater. Des. 2013, 51, 676-682. [CrossRef]

73. Fan, W.; Ji, W.; Wang, L.; Zheng, L.; Wang, Y. A review on cutting tool technology in machining of Ni-based superalloys. Int. J. Adv. Manuf. Technol. 2020, 110, 2863-2879. [CrossRef]

74. Kohlscheen, J.; Bareiss, C. Effect of hexagonal phase content on wear behaviour of AlTiN arc PVD coatings. Coatings 2018, 8, 72. [CrossRef]

75. Hao, G.; Liu, Z. Experimental study on the formation of TCR and thermal behavior of hard machining using TiAlN coated tools. Int. J. Heat Mass Transf. 2019, 140, 1-11. [CrossRef]

76. Fox-Rabinovich, G.S.; Gershman, I.S.; Veldhuis, S. Thin-film PVD coating metamaterials exhibiting similarities to natural processes under extreme tribological conditions. Nanomaterial 2020, 10, 1720. [CrossRef]

77. Sergevnin, V.S.; Blinkov, I.V.; Volkhonskii, A.O.; Belov, D.S.; Chernogor, A.V. Structure formation of adaptive arc-PVD Ti-Al-Mo-N and Ti-Al-Mo-Ni-N coatings and their wear-resistance under various friction conditions. Surf. Coat. Technol. 2019, $376,38$. [CrossRef]

78. Alamgir, A.; Yashin, M.; Bogatov, A.; Viljus, M.; Traksmaa, R.; Sondor, J.; Lümkemann, A.; Sergejev, F.; Podgursky, V. Hightemperature tribological performance of hard multilayer TiN-AlTiN/nACo-CrN/AlCrN-AlCrO-AlTiCrN coating deposited on WC-Co Substrate. Coatings 2020, 10, 909. [CrossRef] 